UNIVERSIDADE DE SÃO PAULO

FACULDADE DE ECONOMIA, ADMINISTRAÇÃO E CONTABILIDADE DEPARTAMENTO DE ECONOMIA

PROGRAMA DE PÓS-GRADUAÇÃO EM ECONOMIA

CRÉDITO HABITACIONAL NO BRASIL: AVANÇOS INSTITUCIONAIS NOS CONTRATOS DE CRÉDITO IMOBILIÁRIO

Natalia Quiroga Cotarelli

Prof. Dr. Gabriel de Abreu Madeira

SÃo PAULO

2014 
Prof. Dr. Marco Antonio Zago

Reitor da Universidade de São Paulo

Prof. Dr. Adalberto Américo Fischman

Diretor da Faculdade de Economia, Administração e Contabilidade

Prof. Dr. Hélio Nogueira da Cruz

Chefe do Departamento de Economia

Prof. Dr. Márcio Issao Nakane

Coordenador do Programa de Pós-Graduação em Economia 


\section{CRÉDITO HABITACIONAL NO BRASIL: AVANÇOS INSTITUCIONAIS NOS CONTRATOS DE CRÉDITO IMOBILIÁRIO}

Dissertação apresentada ao Departamento de Economia da Faculdade de Economia, Administração e Contabilidade da Universidade de São Paulo como requisito para a obtenção do título de Mestre em Ciências.

Orientador: Prof. Dr. Gabriel de Abreu Madeira

\section{Versão corrigida}


FICHA CATALOGRÁFICA

Elaborada pela Seção de Processamento Técnico do SBD/FEA/USP

Cotarelli, Natalia Quiroga

Crédito habitacional no Brasil: avanços institucionais nos contratos de crédito imobiliário / Natalia Quiroga Cotarelli. -- São Paulo, 2014.

$56 \mathrm{p}$.

Dissertação (Mestrado) - Universidade de São Paulo, 2014.

Orientador: Gabriel Abreu Madeira.

1. Crédito imobiliário 2. Contratos 3. Alienação fiduciária 4. Garantia I. Universidade de São Paulo. Faculdade de Economia, Administração e Contabilidade. II. Título.

CDD - 332.722 
À minha família. 


\section{AGRADECIMENTOS}

Agradeço aos meus pais, pelo apoio e amor incondicional. Agradeço também às minhas irmãs, Fernanda e Júlia, que tornaram a minha vida bem mais divertida! Amo muito vocês.

Agradeço aos meus colegas de mestrado pelo companherismo e amizade ao longo desses dois anos. Em especial, agradeço a Bruna, Isabel, Júlia e Luísa, vocês se tornaram muito mais do que colegas de mestrado, vou levar a amizade de vocês para o resto da minha vida.

Agradeço ao Luis, por todo o apoio e companherismo durante os momentos finas da dissertação. Obrigada por estar sempre ao meu lado.

Agradeço ao Banco Central do Brasil, por disponibilizar a base de dados do Sistema de Informações de Crédito (SCR). Em especial, Clodoaldo Annibal, Sergio Mikio e Tony Takeda.

Agradeço a todos os meus familiares e amigos, que foram muito importantes para mim ao longo de toda esta trajetória. Listar todos nominalmente seria muito extenso e injusto, pois certamente faltariam os nomes de pessoas essenciais nesse processo. Muito obrigada a todos.

Agradeço ao meu orientador, Gabriel Madeira, por acreditar no meu projeto, e por toda a ajuda e paciência ao longo do desenvolvimento desta dissertação.

Finalmente, agradeço à CNPQ e FAPESP pelo apoio financeiro. 


\section{RESUMO}

Embora o mercado de crédito imobiliário no Brasil tenha se expandido nos últimos anos, sua participação no Produto Interno Bruto (PIB) está muito abaixo do percentual encontrado em outros países em desenvolvimento. Com isso, o país continua apresentando déficits habitacionais significativos, problema este que tem maior impacto nas famílias de menor renda. Este estudo pretende analisar o impacto da Lei $n \underline{o}$ 10.931, de agosto de 2004, que incluiu a figura jurídica de alienação fiduciária do bem imóvel no ordenamento jurídico nos contratos de financiamento habitacional do Brasil, avaliando a evolução destes para diferentes grupos de mutuários. É consenso na literatura que o mercado de crédito apresenta certas particularidades, como os problemas de informação e comprometimento limitado, especificidades estas que podem gerar racionamento de crédito. Avanços institucionais que alterem os parâmetros dos contratos, e que aumentem a segurança jurídica dos credores podem ajudar no desenvolvimento do mercado de crédito, amenizando estes problemas, e tornando o crédito mais acessível para todos os tipos de mutuários. 


\begin{abstract}
Although the real estate market in Brazil has been expanding in recent years, its share in Gross Domestic Product (GPD) is significantly below the percentage found in other developing countries. Because of this, the country continues to present significant housing deficits. This study aims to analyze the impact of the Law $n^{-}$10.931, from august 2004, which included the legal concept of fiduciary property in the legal system in contracts for the real estate market, comparing the evolution of these contracts for different groups of borrowers. There is a consensus that the credit market has certain peculiarities, such as information problems and limited commitment, which can generate credit rationing. Institutional improvements that alter the parameters of the contracts, and increase legal certainty for creditors may help in the development of the credit market, mitigating these problems, and making credit more accessible for all kinds of borrowers.
\end{abstract}




\section{SUMÁRIO}

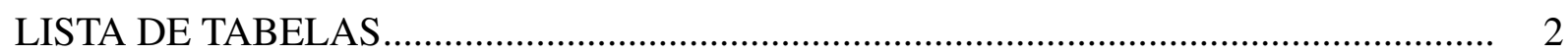

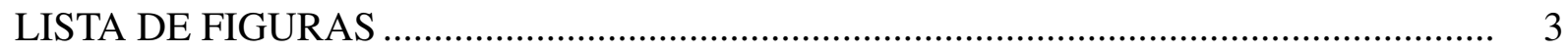

1 INTRODUÇÃO .................................................................................... 5

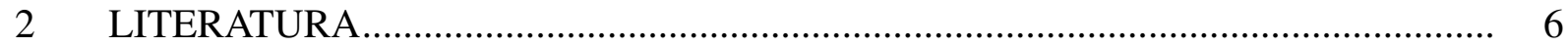

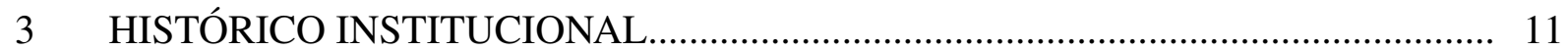

3.1 Sistema Financeiro Habitacional (SFH) ….................................................. 11

3.2 Sistema Financeiro Imobiliário (SFI) ............................................................... 13

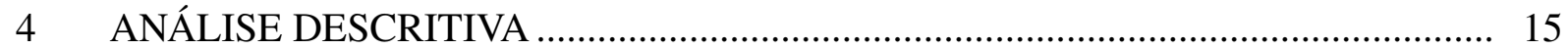

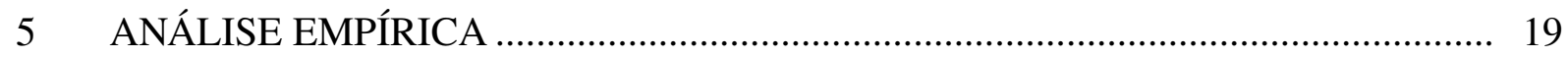

5.1 Primeira Estratégia: Funcionário Público versus Funcionário Privado ..................... 20

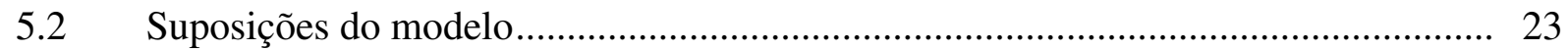

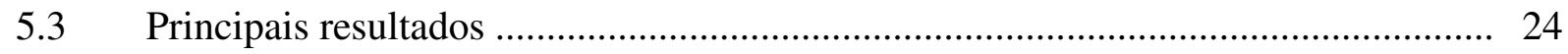

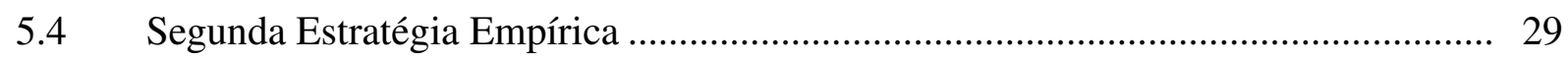

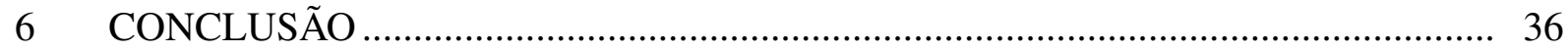

Referências Bibliográficas 39

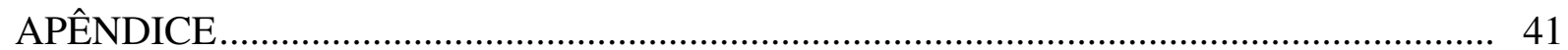




\section{LISTA DE TABELAS}

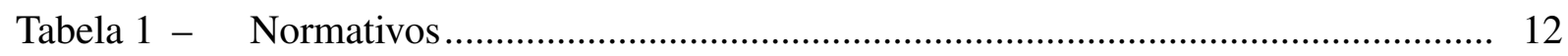

Tabela 2 - Grupo de controle vs. Grupo de tratamento.............................................. 22

Tabela 3 - Variável dependente: Dummy crédito imobiliário ....................................... 24

Tabela 4 - Variável dependente: Valor Financiado ..................................................... 25

Tabela 5 - Variável dependente: Prazo do contrato ................................................... 26

Tabela 6 - Variável dependente: Dummy atraso...................................................... 27

Tabela 7 - Variável dependente: Dummy prejuízo ..................................................... 28

Tabela 8 - Grupo de controle vs. Grupo de tratamento............................................ 31

Tabela 9 - Variável dependente: Valor Financiado .................................................. 32

Tabela 10 - Variável dependente: Prazo do financiamento ............................................. 33

Tabela 11 - Variável dependente: Dummy atraso.................................................... 34

Tabela 12 - Variável dependente: Dummy prejuízo ...................................................... 35

Tabela 13 - Grupo de controle vs. Grupo de tratamento.............................................. 42

Tabela 14 - Variável dependente: Dummy atraso....................................................... 43

Tabela 15 - Variável dependente: Dummy prejuízo ................................................... 44 


\section{LISTA DE FIGURAS}

Figura 1 - Crédito do Sistema Financeiro Nacional (\%PIB) .......................................... 16

Figura 2 - Operações de créditos do SFN à habitação (u.m.c. milhões)............................. 17

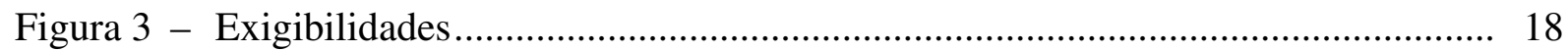

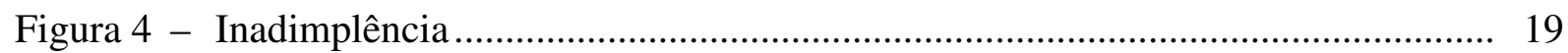

Figura 5 - Número de contratos imobiliários iniciados em cada mês ................................ 20

Figura 6 - Evolução contratos de funcionários privados vs. públicos .............................. 21

Figura 7 - Evolução contratos grupo de controle (tipo AA) ............................................. 30

Figura 8 - Evolução contratos grupo de tratamento (tipo H e HH) .................................. 30

Figura 9 - Evolução contratos grupo de controle (tipo D) ............................................. 36

Figura 10 -Evolução da probabilidade de atraso............................................................ 41

Figura 11 -Evolução da probabilidade de default ........................................................ 41 


\section{INTRODUÇÃO}

O mercado de crédito imobiliário no Brasil vem se expandindo nos últimos anos, como consequência principalmente de dois fatores: estabilização econômica e aperfeiçoamentos institucionais. Contratos de créditos habitacionais têm prazos longos, em geral superiores a 15 anos e que, portanto, exigem um ambiente de estabilidade macroeconômica e uma estrutura institucional que garantam os direitos dos credores.

Mesmo com a atual expansão e fortalecimento do mercado de crédito habitacional no Brasil, sua participação no PIB ainda é de $2,1 \%^{1}$, valor significativamente abaixo do encontrado em países com características econômicas semelhantes. Nesse cenário, o Brasil continua apresentando significativo déficit habitacional, problema este que atinge, de forma mais acentuada, as camadas mais pobres da população.

Assim, estudar como certos aperfeiçoamentos institucionais impactaram os contratos de crédito imobiliário pode ser de grande ajuda para desenvolver novas políticas públicas que prezem pelo cumprimento dos acordos contratuais e, consequentemente, ajudem no desenvolvimento do mercado de crédito no país.

A Lei n⿳⺈ 9.514, de 20 de novembro de 1997, entre outras medidas, criou o instituto da alienação fiduciária de imóveis, o qual mantém a propriedade do bem financiado em nome do credor, até o cumprimento da obrigação, promovendo a redução dos riscos de crédito para as instituições financeiras, comparativamente aos contratos de garantia hipotecária. Já a Lei n⿳丷 10.931, de agosto de 2004, modificou alguns aspectos que tratam da alienação fiduciária, através da inclusão definitiva da figura jurídica da alienação fiduciária do bem imóvel no ordenamento jurídico brasileiro, aumentando o alcance deste instituto de garantia de crédito.

Como a Lei de agosto de 2004 tornou mais ágil o processo de retomada do bem financiado pelo credor, na situação de inadimplência, aumentando o valor residual esperado dos empréstimos com o não pagamento, podemos esperar uma alteração na dinâmica do mercado de crédito depois da instituição desta Lei. Desta maneira, este estudo tem como objetivo analisar empiricamente o impacto da Lei $\mathrm{n}^{-}$10.931, de agosto de 2004, nos contratos de crédito imobiliário no Brasil.

Considerando um modelo no qual, mesmo em equilíbrio, há racionamento de crédito $^{2}$, e sa-

\footnotetext{
${ }^{1}$ Dado do Relatório de Economia Bancária Crédito do Banco Central do Brasil (2008).

${ }^{2}$ Ver Stiglitz e Weiss (1981).
} 
bendo que, antes da Lei, o banco não tinha garantia de retomada do colateral em caso de default, é razoável supor que, neste primeiro momento, a instituição financeira concede empréstimos prioritariamente aos indíviduos menos expostos a choques adversos na renda, ou aqueles considerados de menor risco. Entretanto, após a Lei, com a maior agilidade no processo de retomada da garantia, o credor passa a ofertar o financimanto imobiliário para indivíduos com maior volatilidade da renda, ou mais arriscados. Neste cenário, foi desenvolvido um modelo teórico que busca captar o impacto de aprimimoramentos jurídicos no comportamento dos credores e mutuários.

O presente trabalho encontra-se dividido em sete seções, sendo a primeira constituída por esta introdução. A segunda relaciona este estudo à literatura existente. A seção 3 apresenta o histórico institucional do mercado de crédito imobiliário no Brasil e é seguida pela análise descritiva dos dados de financiamento imobiliário no país. A quinta seção desenvolve o modelo teórico, e é seguida pela apresentação dos resultados empíricos. A última seção conclui este estudo.

\section{LITERATURA}

Uma vasta literatura busca analisar as especificidades do mercado de crédito e seu impacto no desenvolvimento econômico dos países. Em particular, alguns autores como Jaffee e Russell (1976), Stiglitz e Weiss (1981) e Besanko e Thakor (1987) destacam que, mesmo em equilíbrio, o mercado financeiro pode ser caracterizado pelo racionamento de crédito.

Bancos oferecem empréstimos levando em consideração a rentabilidade (taxa de juros e colateral) e o risco do financiamento. Entretanto, a taxa de juros pode alterar o risco conjunto do crédito de duas formas distintas: primeiro, selecionando apenas um tipo de indivíduo (efeito seleção adversa); ou modificando as ações dos mutuários (efeito moral hazard). Vale destacar que ambos os efeitos são diretamente derivados do problema de informação imperfeita presente no mercado de crédito.

Para um dado colateral, um aumento da taxa de juros pode selecionar apenas os indivíduos com investimentos mais arriscados, ao dar incentivos ao mutuário para investir em projetos com maior probabilidade de perda, mas que, em caso de sucesso, geram um retorno maior. Ainda, mantendo os juros fixos, um aumento no colateral também pode resultar em elevação do risco e queda do retorno esperado dos bancos. Stiglitz e Weiss (1981) modelam estes problemas informacionais considerando mutuários avessos ao risco. Entretanto, Wette (1983) identifica os 
problemas de seleção adversa e moral hazard mesmo em um ambiente com indivíduos neutros ao risco.

Barro (1976) destaca a importância do colateral no mercado de crédito. Considerando que o valor do colateral é estocástico no momento em que o empréstimo é negociado, a possibilidade de transferência da garantia para o banco em caso de default incentiva o mutuário a se esforçar mais para pagar o empréstimo. Além disso, o valor que o banco dá à garantia, também é estocástico e pode divergir do valor atribuído pelo mutuário. Esta relação entre bancos e mutuários com valor do colateral tem papel fundamental no modelo de crédito desenvolvido por Barro (1976). Se o banco der um valor à garantia muito menor do que o atribuído pelo mutuário, o processo de default vai gerar uma perda para ambas as partes (dead-wight loss). Sendo assim, a taxa juros paga pelo tomador do empréstimo deve refletir este custo adicional, ponderado pela probabilidade de não pagamento.

Ainda com foco na importância do colateral para o mercado de crédito, Besanko e Thakor (1987) desenvolvem um modelo no qual os bancos podem alterar os termos do contrato (colateral e taxa de juros), de modo a distribuir os mutuários em diferentes classes de risco. Diferentemente de Stiglitz e Weiss (1981), que consideram o retorno médio esperado igual para todos os tipos de indivíduos, neste estudo, a distribuição do retorno dos mutuários de baixo risco exibe uma dominância estocástica de primeira ordem sobre os mais arriscados. Sendo assim, tomadores de empréstimo de baixo risco vão preferir contratos com taxa de juros menores e garantias maiores. Entretanto, Besanko e Thakor (1987) destacam que alguns mutuários podem ter dotações iniciais insuficientes, o que os excluiria do mercado de financiamentos. Mais uma vez, conclui-se que, mesmo em equilíbrio, há racionamento de crédito.

Chan e Thakor (1987) examinam o equilíbrio nos contratos de crédito sob diferentes estruturas de mercado, considerando a presença de informação imperfeita. O primeiro modelo de equilíbrio, utilizado também por Jaffee e Russell (1976), envolve bancos competindo por empréstimos, em um ambiente de oferta perfeitamente elástica de depósitos, com uma taxa de funding do banco exógena e determinada pelo mercado. Neste cenário, mesmo com presença de moral hazard e informação imperfeita, o contrato de equilíbrio é o ótimo (first best), no qual o financiamento ofertado pelo banco é totalmente garantido pelo colateral.

Já na segunda estrutura, as instituições financeiras competem por uma quantidade limitada de depósitos, fazendo com que a taxa de funding seja determinada endogenamente pelo modelo. Neste caso, mesmo que um contrato completamente garantido seja factível, a informação imperfeita e o problema de moral hazard alteram o equilíbrio ótimo (first best). O banco vai calibrar 
os termos do contrato, taxa de juros e colateral, de modo que o mutuário tenha incentivo para maximizar o seu nível de esforço. Nesta estrutura, Chan e Thakor (1987) apontam que um aumento do colateral induz a um maior nível de esforço, enquanto uma taxa de juros mais elevada tem o efeito oposto.

Neste ambiente, duas suposições devem ser feitas: a primeira envolvendo a "qualidade" do mutuário e seu retorno marginal dado um esforço adicional; e a segunda relacionada à utilidade de reserva, que varia dependendo do tipo de mutuário. Explorando os equilíbrios sob diferentes combinações dessas suposições, os autores concluem que, em um ambiente de moral hazard com informação imperfeita, mutuários de alta qualidade podem ser excluídos do mercado de crédito, mesmo que eles possam oferecer uma quantidade ilimitada de colateral e os bancos tenham fundos suficientes para ofertar novos financiamentos. Além disso, dependendo das suposições, os indivíduos que se declaram de melhor qualidade devem oferecer uma quantidade maior de colateral.

Esta dissertação formula um modelo de equilíbrio com racionamento de crédito, semelhante aos descritos anteriormente, porém, mais em linha com Stiglitz e Weiss (1981) e Chan e Thakor (1987). Como em ambos os modelos, considera-se um mercado de competição perfeita, onde instituições financeiras e mutuários querem maximizar os lucros, sendo que os bancos assim o fazem por meio da taxa de juros e colateral recebidos no empréstimo. Através da condição de first best, na qual o mutuário sempre está apto a pagar o financiamento, desenvolve-se diferentes cenários considerando tanto a capacidade do banco de reaver o colateral, como o tipo de cada indivíduo.

Vale destacar que este estudo se difere dos acima citados pelos seguintes motivos: primeiramente, ao contrário de Barro (1976) e Besanko e Thakor (1987), assume-se que bancos e mutuários atribuem o mesmo valor ao colateral. Entretanto, de forma distinta dos demais modelos, foi introduzida a lentidão do sistema judiciário no mercado de crédito imobiliário, que faz com que bancos não consigam resgatar todo o colateral, em caso de não pagamento. Além disso, em contraste ao modelo de Chan e Thakor (1987), considera-se que o colateral não é ilimitado. Por fim, incorporam-se ao modelo dois tipos de indivíduos que têm o mesmo retorno médio, porém, riscos distintos (o agente de baixo risco tem dominância estocástica de segunda ordem sobre o mais arriscado) ${ }^{3}$.

Além do modelo teórico, o presente trabalho também se dispõe a analisar empiricamente o impacto de um aperfeiçoamento institucional nos termos dos contratos de crédito. A estratégia

\footnotetext{
${ }^{3}$ Este tipo de distinção entre agentes também é utilizado em Stiglitz e Weiss (1981).
} 
aqui utilizada se assemelha ao estudo de Visaria (2003). Nele, a autora busca avaliar como o estabelecimento dos Debt Recovey Tribunals $(\mathrm{DRT})^{4}$ na Índia afetou o comportamento de credores e devedores no mercado de crédito. Assim como a Lei no 10.931 , de agosto de 2004, estes tribunais, por seguirem um processo legal simplificado, agilizaram o julgamento e a execução das sentenças. Com isso, é de se esperar que, com os bancos tendo mais segurança jurídica e maior facilidade na recuperação da garantia, o comportamento de mutuários e credores seja modificado.

Dois aspectos específicos na introdução dos DRTs permitiram a identificação dos efeitos dos tribunais no mercado de crédito. Primeiramente, somente ações judiciais envolvendo quantias inferiores a um milhão de rúpias poderiam ser resolvidas nos DRTs. Dívidas de valor superior deveriam seguir o processo legal tradicional. Além disso, os tribunais foram estabelecidos nos estados indianos em momentos distintos. Considerando que o limite monetário e o momento de introdução não estão correlacionados a outros fatores que influenciaram o comportamento de ambas as partes no contrato, foi empregada a metodologia de diferenças em diferenças, definindo como grupo controle aqueles contratos com valor superior a um milhão de rúpias, controlando para a data na qual o tribunal foi implementado em cada região. Com relação à Lei que será analisada neste estudo, o aspecto que permitiu a identificação dos efeitos é a presença de dois tipos de indivíduos, sendo um mais arriscado que o outro.

Visaria (2003) afirma que a criação dos DRTs aumentou a probabilidade de negociação e pagamento das parcelas em atraso e diminuiu a inadimplência de contratos formalizados após a instituição dos tribunais. Além disso, há evidências de mudanças nos termos dos contratos, já que, embora os montantes emprestados não tenham sido significativamente alterados, ocorreu uma redução da taxa de juros.

Edelberg (2004), também de uma perspectiva mais empírica, busca testar a presença de moral hazard e seleção adversa no mercado de crédito automobilístico dos Estados Unidos. O autor encontra evidências robustas de seleção adversa, na qual os devedores se diferenciam escolhendo contratos que variam com relação à taxa de juros e a exigência de colateral. Ex post, investidores mais arriscados tendem a disponibilizar menos garantias, mas pagar taxas de juros mais altas. Além disso, o estudo encontra resultados semelhantes ao da Visária (2003). Dado o problema de moral hazard, o aumento das exigências de garantia (ou maior facilidade do banco em recuperá-las) modificou o comportamento de credores e mutuários, fazendo com que estes últimos se esforçassem mais para cumprir com as suas obrigações.

\footnotetext{
${ }^{4}$ Os DRTs são instituições “quase legais”, responsáveis por mediar ações judiciais de bancos contra os mutuários inadimplentes.
} 
Já com relação aos estudos que visam analisar o mercado de crédito brasileiro, Martins, Ludenberg e Takeda (2008) buscam avaliar o impacto da Lei $n \underline{o}$ 10.931, de agosto de 2004, na recente expansão do financiamento habitacional no país. Através de um estudo econométrico que relaciona o volume de crédito imobiliário concedido por instituições financeiras públicas e privadas a variáveis macroeconômicas e uma variável que identifica a data de instituição da Lei, os autores encontram resultados distintos, a depender da origem dos recursos. Para instituições privadas, a expansão do saldo real de crédito imobiliário foi impulsionada, em grande parte, somente pelo aumento das exigibilidades. Entretanto, avaliando as instituições públicas, o aumento da garantia jurídica para a retomada do bem em caso de não pagamento não só elevou o saldo real do crédito imobiliário, como reduziu as taxas de inadimplência.

O presente estudo se diferencia da análise empírica de Martins, Ludenberg e Takeda (2008) na medida em que, controlando para a origem dos recursos, busca analisar o impacto da Lei $\mathrm{n}-$ 10.931, de agosto de 2004 na estrutura do contrato (montante e prazo), além de avaliar como este aprimoramento jurídico alterou o comportamento de diferentes tipos de mutuários.

Ainda relacionado à dinâmica do mercado de crédito imobiliário no Brasil, Costa (2004) buscou fazer uma análise econométrica dos créditos totais e habitacionais concedidos no país antes da Lei no 10.931 , de agosto de 2004, ser instituída. A autora argumenta que os bancos alocam seus recursos financeiros destinados ao financiamento habitacional no limite mínimo das exigibilidades, evidenciando que o mercado de crédito imobiliário não é uma alocação eficiente para as instituições financeiras. Além disso, o estudo aponta que o financiamento habitacional foi o que menos reagiu aos avanços dos volumes de empréstimo no período pós-real. Sendo assim, estudos como este, que visam mensurar os efeitos de um aprimoramento jurídico no mercado de crédito imobiliário no país, são importantes para avaliar que outras medidas devem ser tomadas, com o objetivo de incentivar o financiamento habitacional.

Alguns autores ainda analisam as especificidades do mercado de crédito de uma perspectiva mais macroeconômica. Este é o caso de Evan e Jovanovic (1989), que argumentam que as restrições de crédito podem limitar o valor ótimo investido em um empreendimento, ou até mesmo excluir alguns indivíduos desta atividade, trazendo distorções na alocação de recursos na economia. Ainda nesta linha de raciocínio, Banerjee e Newman (1993) relacionam as imperfeições no mercado de crédito ao desenvolvimento econômico de determinados países. Segundo os autores, em um cenário de restrição de crédito, negócios que requerem altos níveis de investimento não estão acessíveis para os indivíduos de baixa renda, fazendo com que pessoas mais pobres optem por trabalhar para terceiros, ao invés de se tornarem empreendedores. Estes estudos corroboram a visão deste trabalho de que o mercado de crédito não é só essencial do ponto de vista 
microeconômico, possibilitando o consumo e o aumento do bem estar dos agentes, como também é importantíssimo para o ambiente macroeconômico, impactando de forma significativa o desenvolvimento econômico das nações.

\section{HISTÓRICO INSTITUCIONAL}

O mercado de crédito imobiliário do Brasil pode ser caracterizado por dois grandes marcos institucionais: a criação do Sistema Financeiro Habitacional (SFH) e do Sistema Financeiro Imobiliário (SFI).

\subsection{Sistema Financeiro Habitacional (SFH)}

Em meio à necessidade de elevar os investimentos habitacionais, foi criado, pela Lei $\mathrm{n}^{o}$ 4.380, de 21 de agosto de 1964, o Sistema Financeiro Habitacional (SFH), composto pelo Banco Nacional da Habitação (BNH) ${ }^{5}$ e as Sociedades de Crédito Imobiliário (SCI) ${ }^{6}$. O objetivo principal do sistema era facilitar a aquisição da casa própria pelas famílias de baixa renda.

A formulação do SFH era baseada na concessão de crédito imobiliário com fontes próprias de recursos. A captação dos fundos era derivada das cadernetas de poupança e do Fundo de Garantia por Tempo de Serviço (FGTS). A aplicação dos recursos das cadernetas obedece a critérios de exigibilidade mínima, que variaram ao longo do tempo. Atualmente, por lei, 65\% da captação deve ser destinada a financiamentos habitacionais, sendo que, deste total, $80 \%$ devem ser aplicados em operações do SFH. ${ }^{7}$.Os normativos relacionados à exigibilidade ${ }^{8}$ de encaixes obrigatórios e financiamentos imobiliários desde 1993 estão relacionados na tabela abaixo:

\footnotetext{
${ }^{5} \mathrm{O} \mathrm{BNH}$ tinha como funções gerir os recursos públicos destinados à política habitacional, além de normatizar e fiscalizar as operações de captação de poupança e financiamento imobiliário pelos agentes financeiros privados e especializados.

${ }^{6} \mathrm{As}$ SCI funcionavam como agentes financeiros do sistema e dependiam do BNH para executar as suas funções. Eram restritas as operações de financiamento para construção, venda ou aquisição de habitações.

${ }^{7}$ Resolução no 3.932 , de 16/12/2010

${ }^{8}$ Existem alguns critérios de ponderação superiores a um para o cumprimento dessa exigibilidade. São eles:1,5 para aplicações em imóveis com valor entre $\mathrm{R} \$ 80$ mil e $\mathrm{R} \$ 100$ mil, segundo as regras do SFH; 1,2 para aplicações em CRI, limitadas a 5\% das exigibilidades prevista; 1,5 para os finaciamentos concedidos a taxas de mercado, desde que adotado o instituto do patrimônio de afetação.
} 
Tabela 1: Normativos

\begin{tabular}{|c|c|c|}
\hline Normativos & Encaixes Obrigatórios & Financiamentos imobiliários \\
\hline Resolução no 1.980 , de 30/4/1993 & $15 \%$ & $70 \%{ }^{1}$ \\
\hline Resolução nº 2.088, de 30/6/1994 & $20 \%$ & $70 \% 1$ \\
\hline Resolução nº 2.106, de 31/8/1994 & $30 \%$ & $70 \%^{1}$ \\
\hline Resolução no 2.190 , de 23/8/1995 & $15 \%$ & $70 \%^{1}$ \\
\hline Resolução no 2.458 , de 18/12/1997 & $15 \%$ & $70 \%^{2}$ \\
\hline Resolução n⿳o 2.519, de 29/6/1998 & $15 \%$ & $70 \%^{3}$ \\
\hline Resolução no 2.623 , de 29/7/1999 & $15 \%$ & $60 \%{ }^{3}$ \\
\hline Resolução nº 2.706 , de 30/3/2000 & $15 \%$ & $65 \%^{3}$ \\
\hline Resolução nº 2.968 , de 24/6/2002 & $20 \%$ & $65 \%^{3}$ \\
\hline Resolução n⿳⺈ 3.005, de 30/7/2002 & $20 \%$ & $65 \%{ }^{4}$ \\
\hline Resolução nº 3.177, de 08/3/2004 & $20 \%$ & $65 \%{ }^{5}$ \\
\hline Resolução n⿳⺈ 3.347, de 08/2/2006 & $20 \%$ & $65 \%{ }^{6}$ \\
\hline Resolução no 3.932 , de 16/12/2010 & $20 \%$ & $65 \%^{7}$ \\
\hline
\end{tabular}

1) No mínimo $80 \%$ desse limite deveriam ser aplicados em operações do SFH, podendo o restante ser aplicado a taxas de mercado.

2) No mínimo 30\% e 50\% desse limite deveriam ser aplicados, respectivamente, em operações do SFH e da faixa especial, podendo o restante ser aplicado a taxas de mercado, desde que a metade, no mínimo, em operações de financiamento habitacional.

3) No mínimo $80 \%$ desse limite deveriam ser aplicados em operações do SFH, podendo o restante ser aplicado a taxas de mercado, desde que a metade, no mínimo, em operações de

financiamento habitacional

4) No mínimo $80 \%$ desse limite deveriam ser aplicados em operações do SFH, podendo o restante ser aplicado a taxas de mercado. Estabelecido o decaimento de $1 / 100$ dos critérios do FCVS.

5) No mínimo $80 \%$ desse limite deveriam ser aplicados em operações do SFH, podendo o restante ser aplicado a taxas de mercado. Estabelecido o decaimento de $1 / 50$ dos critérios do FCVS. 6) No mínimo $80 \%$ desse limite deveriam ser aplicados em operações do SFH, podendo o restante ser aplicado a taxas de mercado.Estabelecido o decaimento de $1 / 36$ dos critérios do FCVS. 7) No mínimo $80 \%$ desse limite deveriam ser aplicados em operações do SFH, podendo o restante ser aplicado a taxas de mercado.

As operações do SFH aceitam os dois tipos de garantia, hipoteca e alienação fiduciária, com taxa de juros de até $12 \%$ ao ano e valor de financiamento de no máximo R\$ 650 mil. ${ }^{9}$

Além disso, a Lei $\mathrm{n}^{\circ} \mathbf{4} 4380$ instituiu a correção monetária nos contratos imobiliários, viabilizando os financiamentos de longo prazo. Vale destacar que a correção monetária foi fundamental para o desenvolvimento do financiamento habitacional, até então, limitado a poucas operações realizadas pelas Caixas Econômicas e Institutos de Previdência existentes na época.

\footnotetext{
${ }^{9}$ Para São Paulo, Rio de Janeiro, Minas Gerais e Distrito Federal o valor máximo do financimento é de R\$750 mil, segundo Resolução n⿳⺈-4.271 de 30/9/2013.
} 
A primeira fase do $\mathrm{SFH}$, que vai até meados da década de 70 , foi de grande sucesso. Os depósitos em caderneta de poupança cresceram e os recursos do FGTS se expandiram. Surgiram as sociedades de Crédito Imobiliário e as Associações de Poupança e Empréstimo, formando o Sistema Brasileiro de Poupança e Empréstimo (SBPE), integrado por instituições financeiras especializadas na concessão de créditos habitacionais, que tinham como fonte de recursos os depósitos em caderneta de poupança e os repasses do FGTS feitos pelo BNH. Além disso, para proteger os mutuários, foi criado pelo próprio BNH em 1967, o Plano de Equivalência Salarial/ Categoria Profissional (PES/CP), que previa a correção das parcelas do financiamento de acordo com os ganhos salariais dos mutuários. Posteriormente, também foi criado o Plano de Equivalência Salarial/ Comprometimento de Renda (PES/CR), que limitava a parcela do financiamento em $30 \%$ da remuneração do mutuário. Os eventuais descompassos entre a evolução dos saldos devedores e das prestações ficou conhecido com saldo residual e era absorvido pelo Fundo de Compensação de Variações Salariais (FCVS).

Entretanto, no final da década de 70, com a crise do petróleo seguida da crise da dívida externa, a taxa de inflação disparou no Brasil, aumentando significativamente o descasamento entre os índices de correção dos saldos devedores, que seguiam indiretamente os índices de inflação, e o índice de correção das prestações desses financiamentos que, na maioria das vezes, acompanhavam a evolução dos salários. Nesse cenário, as Associações de Poupança e Empréstimo e as Sociedades de Crédito Imobiliário foram gradualmente substituídas pelos bancos múltiplos na concessão de novos financiamentos. O BNH foi extinto em novembro de 1986, e o Banco do Brasil, Caixa Econômica Federal e Ministério da Fazenda passaram a assumir as suas atribuições.

Este período ainda foi marcado por um grande volume de contratos vencendo, deixando tanto os bancos como os governos com um enorme déficit do FCVS. ${ }^{10}$

\subsection{Sistema Financeiro Imobiliário (SFI)}

Para tentar enfrentar a crise que se instalava no mercado de crédito habitacional, foi criado, pela Lei no 9.514, de 20 de novembro de 1997, o Sistema Financeiro Imobiliário (SFI), que estabeleceu o instituto da alienação fiduciária de imóveis, permitindo a redução dos riscos das instituições financeiras nas operações de crédito imobiliário. A adoção da alienação fiduciária de bem imóvel, ao manter a propriedade em nome do financiador, garantiu maior segurança

\footnotetext{
${ }^{10} \mathrm{O}$ déficit do FCVS foi estimado em R $\$ 107$ bilhões em 2000, data em que foi instituída a legislação que regulou as renegociações das dívidas e responsabilidades do FCVS.
} 
jurídica ao crédito imobiliário comparativamente aos contratos com garantia hipotecária.

Com relação ao mercado primário, o SFI se diferencia do SFH por não estabelecer limites de financiamentos ou tetos para as taxas de juros cobradas nas operações de crédito imobiliário, além de só permtir, como garantia, a alienação fiduciária.

Além disso, a Lei de 1997 destaca-se pela criação das companhias securitizadoras imobiliárias, organizadas como sociedades por ações, responsáveis por adquirir créditos imobiliários de instituições financeiras. Esses créditos podem ser transformados em Certificado de Recebíveis Imobiliários (CRIs). Para os investidores de CRIs, o regime fiduciário representa uma segurança adicional, pois significa a constituição de um patrimônio separado, que não estará sujeito ao cumprimento das demais obrigações da companhia securitizadora, inclusive, em relação a outras emissões de CRIs.

Apesar de apresentar importantes inovações, o SFI não atingiu os resultados esperados, principalmente na área habitacional. Com isso, o governo editou, em setembro em 2001, duas medidas provisórias: a MP $\mathrm{n}^{\underline{o}}$ 2.221, que criou a figura jurídica do patrimônio de afetação, segregando os recursos captados para financiamento de uma obra, do patrimônio da incorporadora; e a MP no 2.223, que instituiu dois novos títulos, as Letras de Crédito Imobiliário (LCI) e as Cédulas de Crédito Imobiliário (CCI). Com estas medidas, as alternativas de captação de recursos pelos agentes financeiros responsáveis pela oferta de crédito imobiliário, antes restritas às captações da caderneta de poupança e às Letras Hipotecárias, foram ampliadas, facilitando as operações de crédito atreladas à alienação fiduciária, hipotecas ou garantias reais. Entretanto, a não conversão das MPs 2.221 e 2.223 em lei, as altas taxas de juros e a lentidão do sistema jurídico, que também questionou a propriedade nos contratos de alienação fiduciária, impediram uma expansão mais forte das operações de financiamento imobiliário.

Nesse cenário foi implementada a Lei $\mathrm{n}^{\circ}$ 10.931, de 2 de agosto de 2004, que, além de incorporar os avanços das medidas provisórias $\mathrm{n}^{\underline{o}} 2.221$ e $\mathrm{n}-2.223$, incluiu definitivamente a figura jurídica da alienação fiduciária do bem imóvel no ordenamento jurídico brasileiro, reforçando a utilização deste instrumento. Além disso, segundo Maciel (2009, p. 5), "entre as principais alterações promovidas pela lei ( $\mathrm{n}^{-}$- 10.931) estão a antecipação do momento em que ocorre a consolidação da propriedade e da posse plena do bem no patrimônio do credor, que agora se dá cinco dias após cumprida a liminar de busca e apreensão e não mais com a sentença, como previa a lei anteriormente; e a impossibilidade de purgação da mora, somente sendo possível a restituição do bem mediante pagamento da integralidade da dívida, no prazo de cinco dias após cumprida a liminar." 
A Lei no 10.931 também criou a Cédula de Crédito Bancário e promoveu a desoneração tributária dos títulos imobiliários, que passaram a ser isentos de Imposto de Renda. Estas alterações aumentaram a segurança jurídica dos contratos e a liquidez dos financiamentos imobiliários tradicionais, permitindo que os créditos concedidos no âmbito do SFH pudessem ser securitizados e negociados no âmbito do SFI, criando-se, na prática, uma ponte entre os dois sistemas.

Entretanto, a retomada do financiamento imobiliário só foi possível com a resolução do problema do déficit do FCVS. A Lei $n^{o}$ 10.150, de 21 de dezembro de 2000, regulou a novação e a renegociação das dívidas e responsabilidades do FCVS. Posteriormente, a Resolução n⿳o 3.005, de 30 de julho de 2002, estabeleceu que os créditos do FCVS deveriam ser computados como financiamentos imobiliários até o mês subsequente à novação. Depois disso, seus valores computáveis como financiamentos imobiliários foram reduzidos em 1/100 a cada mês. A Resolução CMN no 3.177, de 8 e março de 2004, acelerou o decaimento para 1/50, e reduziu a remuneração dos recursos não aplicados depositados no Banco Central de 100\% da Taxa Referencial (TR) para $80 \%$. Por fim, a Resolução $\mathrm{CMN} \mathrm{n}^{\circ}$ 3.347, de 8 de fevereiro de 2006, aumentou para 1/36 o decaimento da utilização do FCVS para fins de cumprimento das exigibilidades de financiamento habitacional.

\section{ANÁLISE DESCRITIVA}

No final de 1994, iniciou-se o processo de estabilização macroeconômica, que propiciou um ambiente mais favorável ao crescimento de crédito no Brasil. Entretanto, apenas em meados de 2003, pode-se observar uma tendência mais clara de expansão do crédito. O volume de crédito total do Sistema Financeiro Nacional saiu de 24,6\% do PIB em junho de 2003 para 44,6\% do PIB em dezembro de 2009 (ver figura 1). 
Figura 1: Crédito do Sistema Financeiro Nacional (\%PIB)

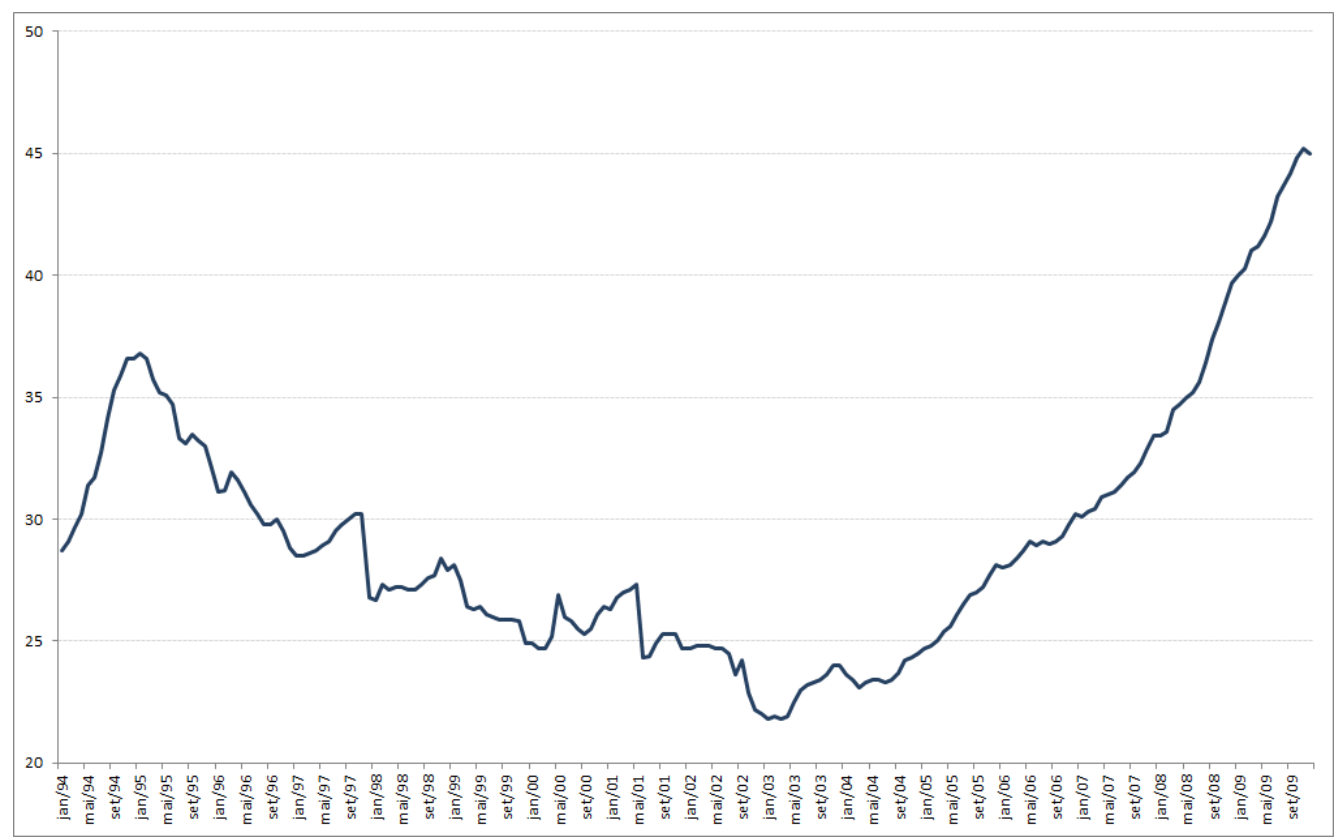

Este crescimento do crédito é resultado principalmente de avanços macroeconômicos e institucionais conquistados nos últimos anos, e que hoje se reflete em um ambiente menos instável para o desenvolvimento do crédito imobiliário. Vale destacar que o crescimento mais robusto do financiamento habitacional começou a ser verificado no começo de 2005 , fazendo com que a sua participação saísse de 1,33\% do PIB no final de 2004 (22,8 bilhões de u.m.c.) para 2,10\% (55,4 bilhões de u.m.c.) em dezembro de $2008^{11}$ (ver figura 2). Além disso, esta trajetória de crescimento tem sido liderada pelo financiamento concedido por instituições públicas; por isso, no presente estudo, a origem do financiamento imobiliário é utilizada como variável de controle para analisar o impacto da Lei de $\mathrm{n}^{\underline{o}} 10.931$, de 2 de agosto de 2004.

\footnotetext{
${ }^{11}$ A queda acentuada da proporção de crédito imobiliário com relação ao PIB em 2001 é resultado das transferências dos créditos das carteiras imobiliárias das instituições públicas para a Empresa de Gestão de Ativos (Emgea).
} 
Figura 2: Operações de créditos do SFN à habitação (u.m.c. milhões)

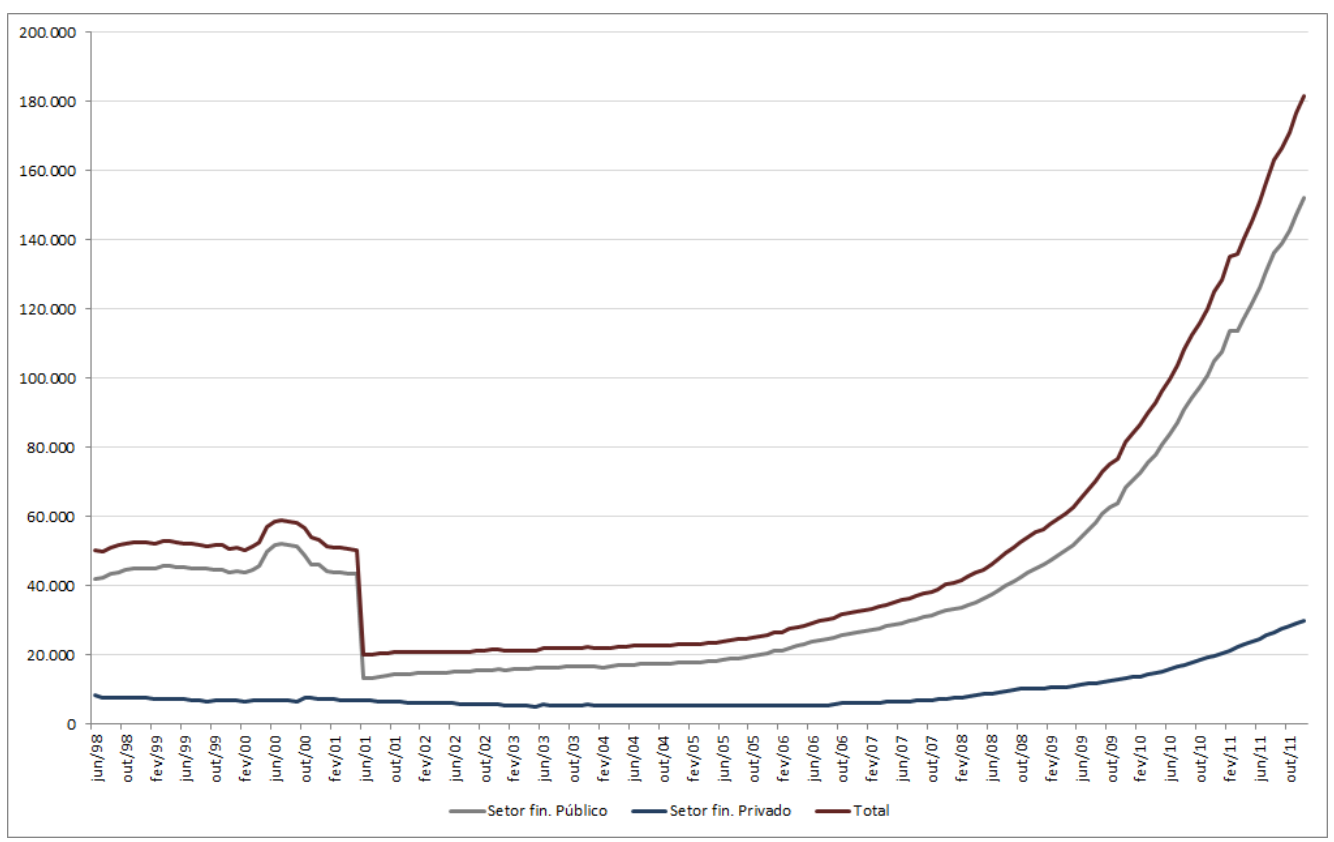

Para o objetivo do presente estudo, é importante analisar se o recente aumento dos financiamentos imobiliários é resultado dos avanços institucionais e macroeconômicos do período, ou somente da obrigatoriedade das aplicações compulsórias das instituições financeiras, que refletiram em um aumento dos recursos aplicados em caderneta de poupança e na exclusão gradual dos créditos do FCVS determinados pela Resolução CMN nº 3.005, de 2002, somados à menor remuneração dos recursos não aplicados depositados no Banco Central, de acordo com a Resolução CMN nº 3.177, de 2004. ${ }^{12}$

Nesse sentido, alguns pontos devem ser analisados de maneira mais aprofundada. A rentabilidade da caderneta de poupança, quando comparada aos retornos dos títulos de renda fixa e dos certificados de depósitos bancários, é negativamente correlacionada com a taxa Selic. Isso ocorre porque a poupança tem rentabilidade praticamente constante ( $6 \%$ ao ano mais Taxa Referencial) ${ }^{13}$, enquanto a rentabilidade dos outros dois ativos está fortemente correlacionada com a Taxa Selic. Assim, deve-se esperar que períodos de queda da taxa Selic sejam acompanhados de aumento na captação de recursos via caderneta de poupança, o que consequentemente eleva as exigibilidades em aplicações no setor imobiliário.

\footnotetext{
${ }^{12}$ A Resolução n⿳o 3.177 definiu que os recursos não aplicados passariam a ser remunerados a $80 \%$ da TR, e não mais a $100 \%$.

${ }^{13}$ Em 2012, a legislação referente à remuneração dos depósitos de poupança foi alterada. De acordo com a legislação atual, a remuneração dos depósitos é composta de duas parcelas: a remuneração básica, dada pela TR, e uma remuneração adicional, que depende da Taxa Selic vigente no período.
} 
Figura 3: Exigibilidades

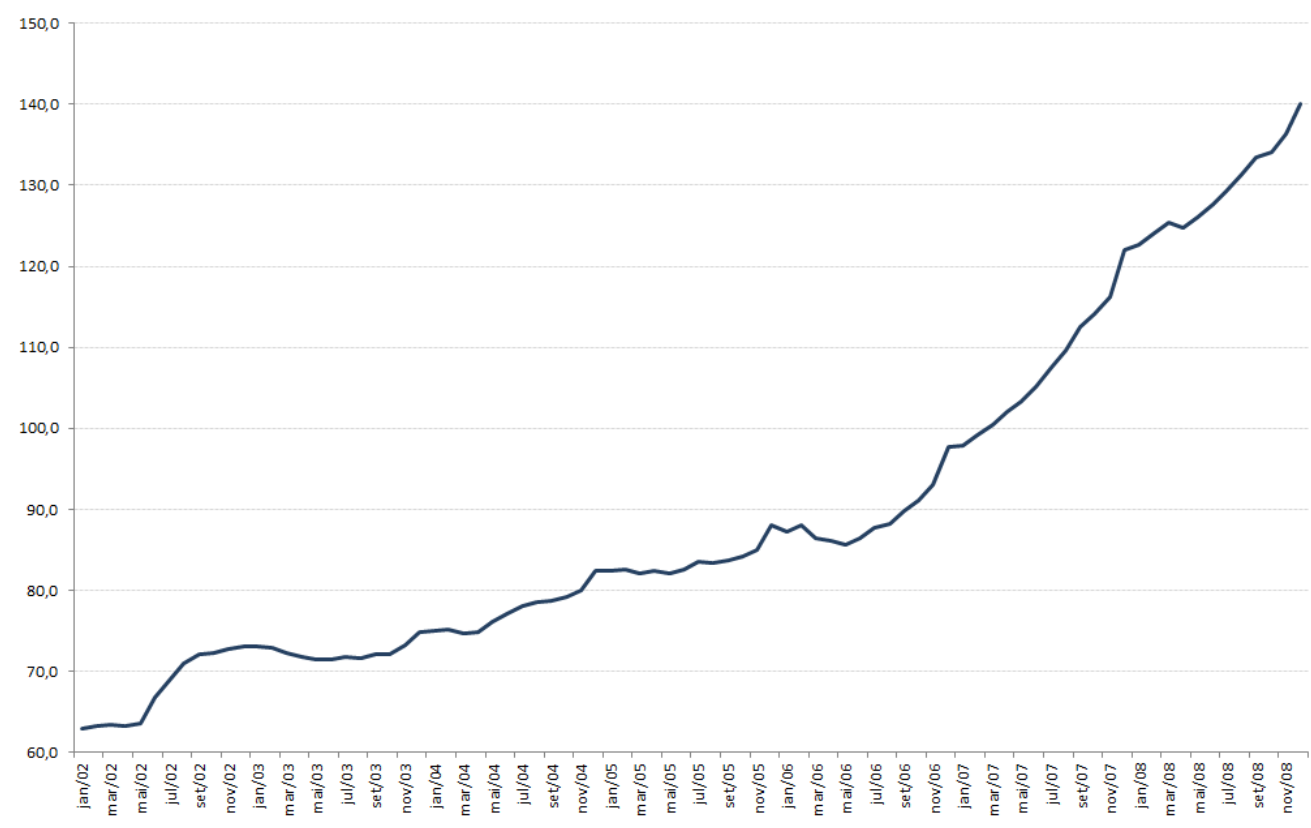

O gráfico 3 revela que, embora as exigibilidades tenham aumentado entre janeiro de 2002 e dezembro de 2008, vemos que a forte expansão ocorreu principalmente a partir do começo de 2006. Esta alta das exigibilidades, provocada pelo expressivo aumento dos depósitos de poupança, pode contaminar os resultados do estudo. Um forte ritmo de expansão das exigibilidades pode fazer com que algumas instituições financeiras acabem por oferecer crédito a clientes mais arriscados, superestimando o impacto da Lei $\mathrm{n}^{-}$10.931, de agosto de 2004. Para evitar este problema, o presente estudo foca sua análise nos indivíduos que receberam financiamento imobiliário entre agosto de 2003 e agosto de 2005 e, portanto, foram menos expostos ao fenômeno da alta das exigibilidades.

Já com relação à taxa de inadimplência, observa-se um recuou na parcela de contratos com mais de três prestações atrasadas. Parte recente desta queda é consequência da estabilização econômica e dos ganhos de renda real. No entanto, através do gráfico 4, pode-se observar uma queda mais acentuada da inadimplência a partir do final de 2004, resultado das melhorias instituicionais implementadas pela Lei $\mathrm{n}^{-}$10.931. 
Figura 4: Inadimplência

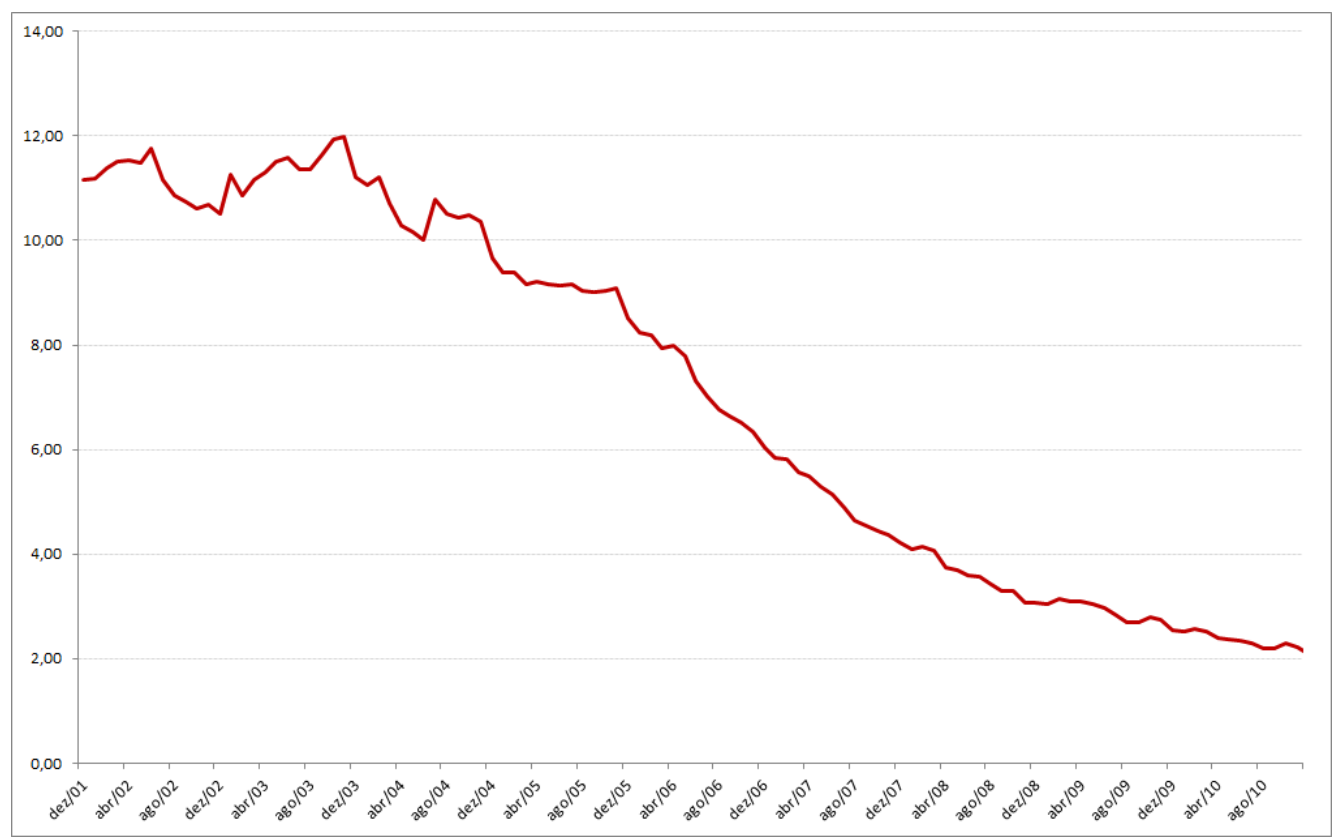

\section{ANÁLISE EMPÍRICA}

A extração da base de dados partiu de 98.116 CPFs que tiveram operações de financiamento imobiliário registradas no Sistema de Informação de Crédito do Banco Central do Brasil (SCR) entre os meses de agosto de 2003 até agosto de 2005, de oito regiões metropolitanas: São Paulo, Rio de Janeiro, Belo Horizonte, Porto Alegre, Curitiba, Salvador, Fortaleza e Recife. Foram extraídas todas as operações de crédito (empréstimo, financiamentos, coobrigações, etc.), mês a mês, seguindo 26 variáveis, até dezembro de 2011. Ao todo, temos 113.109 contratos, sendo que destes, 74.276 são contratos de financiamento habitacional.

O gráfico abaixo mostra o número de contratos imobiliários iniciados em cada mês, de agosto de 2003 até agosto de 2005. 
Figura 5: Número de contratos imobiliários iniciados em cada mês

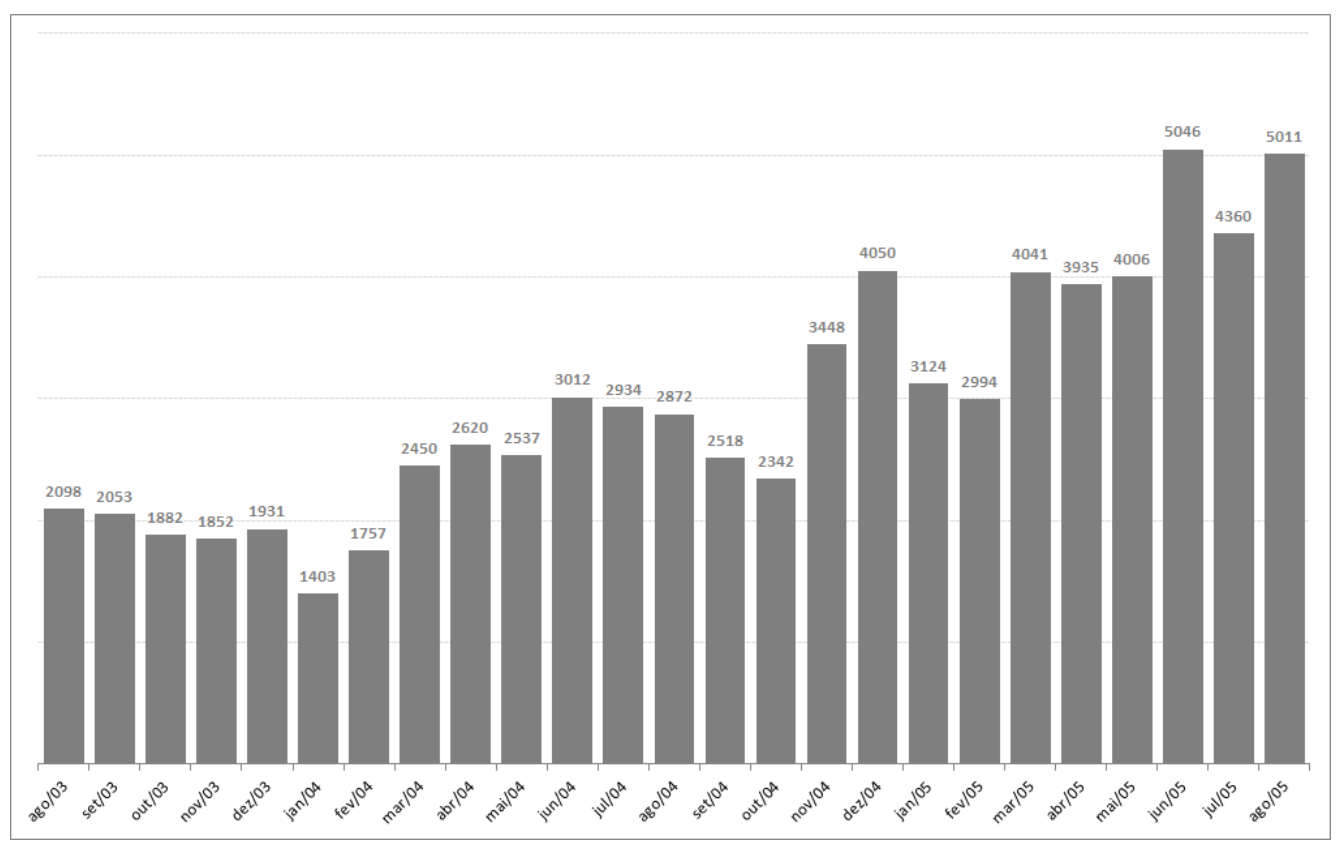

Estes contratos foram acompanhados até dezembro de 2011 e geraram 1.163.200 observações. Com o objetivo de avaliar o impacto do aprimoramento jurídico instituído com a Lei $\mathrm{n}^{\mathrm{o}} 10.931$ de agosto de 2004, serão adotadas duas estratégias empíricas, descritas abaixo.

\subsection{Primeira Estratégia: Funcionário Público versus Funcionário Privado}

Sabe-se que um funcionário público, normalmente, tem maior estabilidade no trabalho do que um funcionário privado. Sendo assim, considera-se que, em geral, trabalhadores de instituições públicas terão probabilidade menor de sofrerem um choque de renda negativo do que os empregados privados. Nesse cenário, controlando para a renda mensal média de cada indivíduo, temos que, em um ambiente de baixa garantia jurídica para o credor, taxas de juros controladas e exigências mínimas de oferta de crédito, as instituições financeiras tendem a conceder o financiamento imobiliário aos indivíduos com menor volatilidade na renda, que neste primeiro momento serão representados pelos funcionários públicos.

Descrito isso, uma lei que aprimore o processo jurídico de retomada do bem financiado, como é o caso da Lei $\mathrm{n}$ - 10.931, de 2 de agosto de 2004, deve tornar a decisão do banco de concessão de crédito menos dependente da volatilidade de renda de cada indivíduo, já que, em caso de default, a instituição financeira receberá o colateral do empréstimo. Com isso, os bancos estarão aptos a ofertar o financiamento habitacional para todos os tipos de funcionários, sejam eles públicos 
ou privados.

Partindo desta suposição, considera-se, então, que a Lei estudada neste trabalho deve ter impactado de forma mais explícita os contratos imobiliários dos funcionários privados do que dos funcionários públicos. Analisando a base de dados, encontra-se a seguinte evolução dos contratos por tipo de agente.

Figura 6: Evolução contratos de funcionários privados vs. públicos

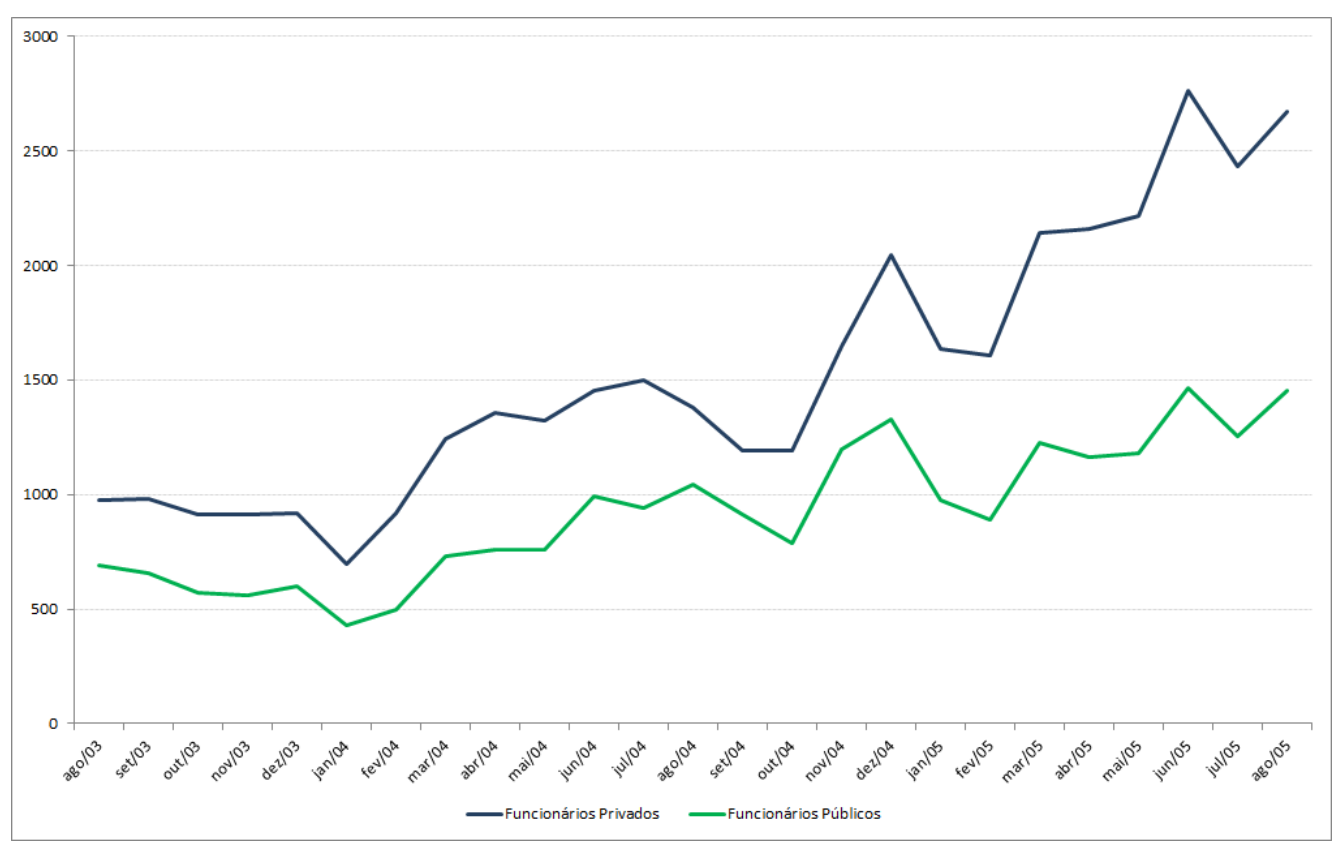

Nesta primeira análise, compondo o grupo de controle, estão os funcionários públicos, enquanto os empregados de instituições privadas participam do grupo de tratamento. Como variáveis que caracterizam o contrato, temos: a origem dos recursos ${ }^{14}$ e o risco de cada operação ${ }^{15}$. Já com relação aos mutuários, controlamos pelo sexo, renda mensal ${ }^{16}$ e região metropolitana onde o indivíduo reside ${ }^{17}$.

\footnotetext{
${ }^{14}$ Foi utilizada uma variável de identificação de cada instituição financeira ("falso CPF") como proxy para a origem de recursos. Verificou-se que uma instituição financeira detém a maior parte das concessões de crédito imobiliário no país. Sendo assim, utilizou-se uma dummy da origem do recurso para caracterizar esta instituição financeira.

${ }^{15}$ As operações são classificadas em dez tipos de riscos. Em ordem crescente, temos: AA,A,B,C,D,E,F,G,H,HH

${ }^{16} \mathrm{~A}$ renda mensal foi dividida em oito faixas pelo número de salários mínimos que o mutuário recebe por mês: 0,0-1,1-2,2-3,3-5,5-10,10-20,>20.

${ }^{17}$ Foi utilizada uma variável dummy para cada uma das oito regiões metropolitanas analisadas.
} 
Tabela 2: Grupo de controle vs. Grupo de tratamento

\begin{tabular}{ccc}
\hline \hline & Funcionário Público & Funcionário Privado \\
\hline Número de observações & & \\
Renda Mensal & 135.445 & 315.445 \\
Proporção de homens & $5-10$ s.m. & $5-10$ s.m. \\
Idade & $47 \%$ & $66 \%$ \\
RM: Fortaleza & 51 anos & 47 anos \\
RM: Recife & $1,7 \%$ & $1,6 \%$ \\
RM: Salvador & $1,0 \%$ & $1,0 \%$ \\
RM: Belo Horizonte & $2,5 \%$ & $1,8 \%$ \\
RM: Rio de Janeiro & $6,4 \%$ & $6,5 \%$ \\
RM: São Paulo & $12 \%$ & $13 \%$ \\
RM: Curitiba & $45 \%$ & $46 \%$ \\
RM: Porto Alegre & $4,5 \%$ & $8,1 \%$ \\
Prazo & $26,9 \%$ & $19 \%$ \\
Montante financiado & 11 anos & 12 anos \\
Origem do recurso & R \$ 78.169 & R $\$ 67.961$ \\
Percentual de contratos atrasados & $73 \%$ & $64 \%$ \\
Percentual de prejuízos & $1 \%$ & $2 \%$ \\
Percentual de contratos mais arriscados & $14 \%$ & $3 \%$ \\
\hline \hline
\end{tabular}

Além de avaliar como a Lei no 10.931 afetou o comportamento dos mutuários, é válida uma análise sobre o impacto nos termos do contrato, quais sejam: valor financiado e prazo do financiamento. Assim sendo, estima-se a seguinte equação:

$$
y_{i t}=\alpha+\beta_{1} \text { dlei }_{i t}+\beta_{2} \text { dpriv }_{i t}+\beta_{3} \text { dprivlei } i_{i t}+\gamma X_{i t}+\varepsilon_{i t}
$$

Onde $y_{i t}$ são as variáveis de interesse, que podem ser o valor financiado, o prazo do financiamento ou a probabilidade de atraso e default, no mês t, para cada contrato i. A variável dlei é uma dummy igual a um se a data de início do contrato for posterior a agosto de 2004, e zero caso contrário; dpriv também é uma dummy, que assume o valor um quando o mutuário é funcionário privado e zero caso contrário; e dprivlei é a interação entre estas duas variáveis. $\mathrm{O}$ vetor $\mathrm{X}$ representa as variáveis de controle tanto para o contrato como para o mutuário. 


\subsection{Suposições do modelo}

A identificação correta do impacto da Lei $\mathrm{n}^{\underline{o}} 10.931$ neste modelo depende da suposição de exogeneidade do choque. Como a Lei de alienação fiduciária foi instituída ao mesmo tempo, em todo o país, atingindo todos os contratos imobiliários de todas as pessoas físicas, podese supor com facilidade que este foi um acontecimento exógeno. Além disso, para estimação apropriada, é necessário que os grupos de controle e tratamento sejam adequados, ou seja, caso não tivesse ocorrido o evento exógeno (instituição da lei), a trajetória destes dois grupos deveria ser paralela ${ }^{18}$. Como esta não é uma hipótese possível de ser testada, o presente estudo faz algumas análises para tentar encontrar alguma evidência que corrobore a suposição de que os funcionários privados foram mais afetados do que os públicos. Para isso, utiliza-se os dados da Pesquisa Nacional de Amostras de Domicílios (Pnad), elaborada pelo IBGE, entre os anos de 2003 e 2006, para a estimação do seguinte modelo:

$$
d \text { finan }=\alpha+\beta_{1} d \text { lei }+\beta_{2} d \text { priv }+\beta_{3} d \text { privle } i_{i t}+\gamma \text { controles }+\varepsilon
$$

Onde dfinan é uma variável dummy igual a 1 se o indivíduo possui crédito imobiliário e zero caso contrário; dlei é a variável que assume valor igual a um depois de agosto de 2004; dpriv é variável dummy que identifica se a pessoa trabalha em instituição privada; e controles são as variáveis idade do representante do domicílio, anos de estudo, renda mensal da família, número de residentes por domicílio e dummies para os anos e para a região de residência do entrevistado.

Pela Tabela $4{ }^{19}$, colunas I - IV, observa-se que um funcionário privado tem probabilidade menor de obter crédito imobiliário em um primeiro momento. Entretanto, depois da lei, os trabalhadores de instituições privadas passaram a ter uma probabilidade positiva de contrair um financiamento habitacional. Considerando todos os controles, um funcionário privado, após agosto de 2004 , tem 0,4 ponto percetual a mais de probabilidade de conseguir um empréstimo imobiliário do que anteriormente.

Embora esta não seja uma prova formal, a análise acima fornece um bom indicativo de que, pelo menos com relação ao número de contratos, os funcionários privados foram mais impactados pela Lei do que os servidores públicos.

\footnotetext{
${ }^{18}$ Os gráficos da evolução das variáveis dependentes probabilidade de defaut e atraso, antes da lei, para os dois grupos, estão no Apêndice

${ }^{19}$ Utilizou-se o método de Mínimos Quadrados Ordinários (MQO). Os resultados utilizando os modelos probit e logit foram similares
} 
Tabela 3: Variável dependente: Dummy crédito imobiliário

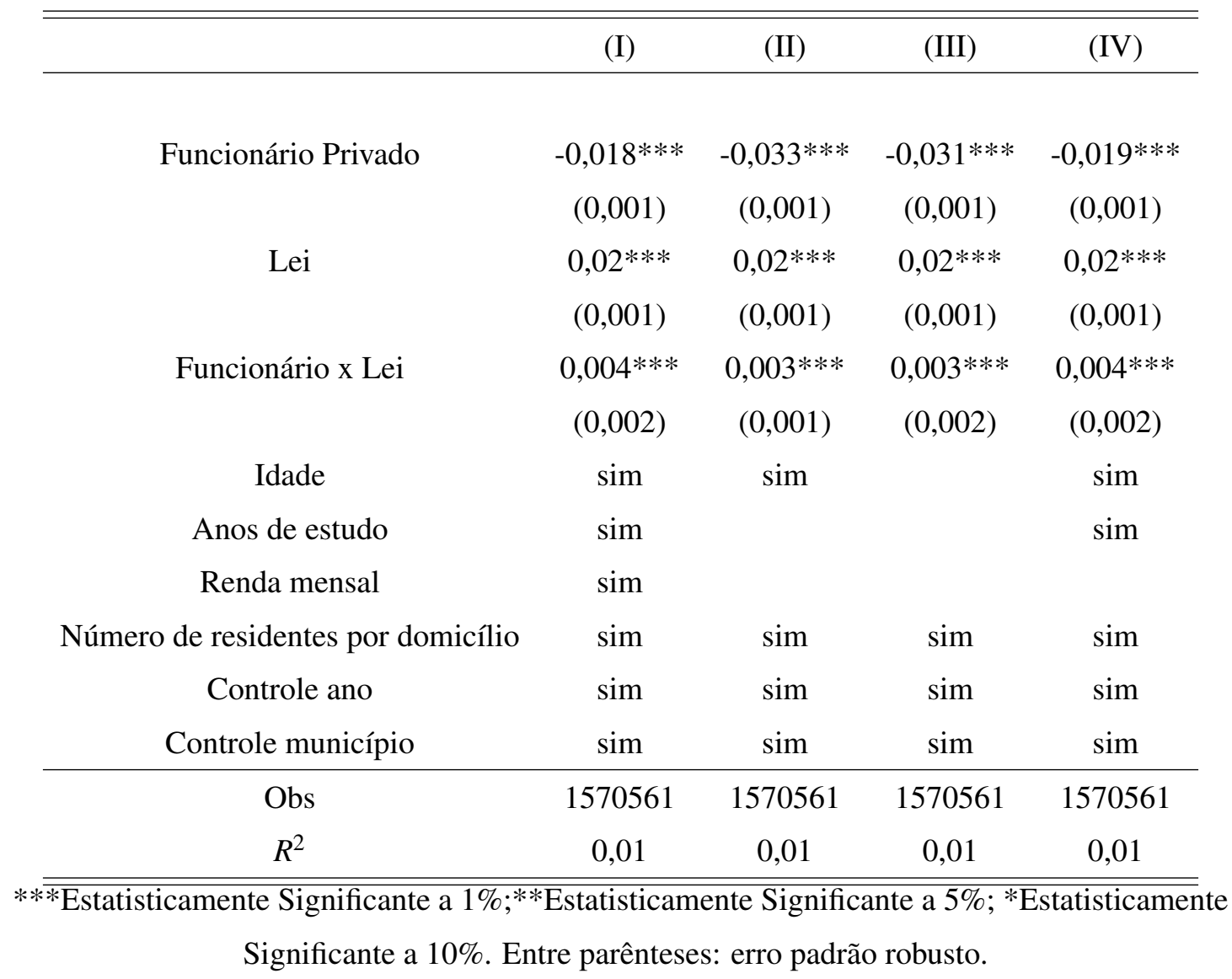

\subsection{Principais resultados}

Estimando a equação 13 através do método de Mínimos Quadrados Ordinários (MQO), os resultados corroboram a suposição inicial deste estudo de que os termos dos contratos imobiliários, principalmente daqueles oferecidos aos funcionários privados, foram impactados pela Lei $\mathrm{n}^{o}$ 10.931. Na coluna (I) da Tabela 5, inserindo as variáveis de controle para o município de residência do mutuário, depois da lei de alienação fiduciária, o valor do empréstimo subiu, em média, $\mathrm{R} \$ 22.555$. Além disso, funcionários privados têm, em média, financiamentos com valor de R \$ 6.645 inferiores aos dos empregados públicos. Entretanto, após agosto de 2004, os trabalhadores de instituições privadas passaram a ter um empréstimo $\mathrm{R} \$ 13.832$ superior. $\mathrm{O}$ resultado é estatisticamente significante independente da especificação do modelo, mesmo não controlando para o município do indivíduo que contraiu o empréstimo.

Estes resultados sinalizam que, com a maior segurança jurídica, os bancos puderam aumentar o montante dos empréstimos, principalmente daqueles que eram ofertados aos funcionários 
privados.

Tabela 4: Variável dependente: Valor Financiado

\begin{tabular}{|c|c|c|c|c|c|}
\hline & (I) & (II) & (III) & (IV) & (V) \\
\hline Funcionário Privado & $\begin{array}{c}-6.645^{* * *} \\
(240,2)\end{array}$ & $\begin{array}{c}-6.614 * * * \\
(289,8)\end{array}$ & $\begin{array}{c}-5.064 * * * \\
(207,9)\end{array}$ & $\begin{array}{c}-10.653 * * * \\
(241,9)\end{array}$ & $\begin{array}{c}-11.635 * * * \\
(228,6)\end{array}$ \\
\hline Lei & $\begin{array}{c}22.555 * * * \\
(207,5)\end{array}$ & $\begin{array}{c}22.519 * * * \\
(210,5)\end{array}$ & $\begin{array}{c}25.625 * * * \\
(207,9)\end{array}$ & $\begin{array}{c}25.104 * * * \\
(215,9)\end{array}$ & $\begin{array}{c}21.051 * * * \\
(207,1)\end{array}$ \\
\hline Funcionário x Lei & $\begin{array}{c}13.832 * * * \\
(396,4)\end{array}$ & $\begin{array}{c}13.815^{* * *} \\
(483,8)\end{array}$ & $\begin{array}{c}13.881 * * * \\
(396,7)\end{array}$ & $\begin{array}{c}13.241 * * * \\
(402,5)\end{array}$ & $\begin{array}{c}14.830 * * * \\
(398,3)\end{array}$ \\
\hline Tendência de tempo & $\begin{array}{c}-0,011 * * * \\
(0,001)\end{array}$ & $\begin{array}{c}-0,011 * * * \\
(0,001)\end{array}$ & $\begin{array}{c}-0,011 * * * \\
(0,001)\end{array}$ & $\begin{array}{c}-0,014 * * * \\
(0,001)\end{array}$ & $\begin{array}{c}-0,04 * * * \\
(0,001)\end{array}$ \\
\hline Origem de recursos & $\begin{array}{c}13.621 * * * \\
(525,2)\end{array}$ & $\begin{array}{c}13.494 * * * \\
(483,9)\end{array}$ & $\begin{array}{c}13.685^{* * *} \\
(525,3)\end{array}$ & $\begin{array}{c}24.621 * * * \\
(511,8)\end{array}$ & $\begin{array}{c}16.672 * * * \\
(500,8)\end{array}$ \\
\hline Risco & $\begin{array}{l}908 * * * \\
(387,8)\end{array}$ & & $\begin{array}{c}1.086^{* * * *} \\
(387,7)\end{array}$ & $\begin{array}{c}-5.445^{* * *} \\
(391,8)\end{array}$ & $\begin{array}{c}4.315^{* * * *} \\
(436,3)\end{array}$ \\
\hline Prazo & $\begin{array}{c}1.698 * * * \\
(170,9)\end{array}$ & $\begin{array}{c}1.696 * * * \\
(170,0)\end{array}$ & $\begin{array}{c}1.701 * * * \\
(170,9)\end{array}$ & $\begin{array}{c}1.703 * * * \\
(171,3)\end{array}$ & $\begin{array}{c}1.496 * * * \\
(165,3)\end{array}$ \\
\hline Sexo & $\begin{array}{c}8.680 * * * \\
(151,7)\end{array}$ & $\begin{array}{c}8.692 * * * \\
(151,3)\end{array}$ & & $\begin{array}{c}14.017 * * * \\
(166,8)\end{array}$ & $\begin{array}{c}7.017 * * * \\
(154,9)\end{array}$ \\
\hline Renda Mensal & $\begin{array}{c}13.102 * * * \\
(75,5)\end{array}$ & $\begin{array}{c}13.071 * * * \\
(76,4)\end{array}$ & $\begin{array}{c}13.493^{* * * *} \\
(78,0)\end{array}$ & & $\begin{array}{c}12.637 * * * \\
(74,5)\end{array}$ \\
\hline Obs & 1163200 & 1163200 & 1163200 & 1163200 & 1163200 \\
\hline$R^{2}$ & 0,11 & 0,11 & 0,11 & 0,11 & 0,11 \\
\hline
\end{tabular}

*****Estatisticamente Significante a 1\%;**Estatisticamente Significante a 5\%; *Estatisticamente

Significante a 10\%. Entre parênteses: erro padrão robusto. Apenas na coluna (V) não foram utilizadas as dummies dos municípios.

Quando considerado como variável dependente o prazo do contrato (em dias) o impacto da Lei no 10.931 é diferente dependendo das variáveis inseridas no modelo. Considerando a estimação com todas as variáveis de controle, inclusive as dummies de municípios, depois de agosto de 2004, os contratos ficaram em média 38 dias mais curtos. Entretanto, o efeito da lei nos contratos dos funcionários privados parece ser mais consistente. Trabalhadores de instituições privadas têm, em média, financiamentos com prazos menores. Porém, com a introdução da Lei, os contratos de trabalhadores privados foram, em média, estendidos em aproximadamente 468 
dias.

Também é interessante notar que o risco do agente tem impacto significativo no prazo de financiamento. Um indivíduo considerado mais arriscado tem um contrato com maturidade inferior a dois anos.

Tabela 5: Variável dependente: Prazo do contrato

\begin{tabular}{cccccc}
\hline \hline & $(\mathrm{I})$ & $(\mathrm{II})$ & $(\mathrm{III})$ & $(\mathrm{IV})$ & $(\mathrm{V})$ \\
\hline \multirow{2}{*}{ Funcionário Privado } & $-148^{* * * *}$ & $-175^{* * *}$ & $-183^{* * *}$ & $-196^{* * * *}$ & 16 \\
& $(13,8)$ & $(13,8)$ & $(13,1)$ & $(13,2)$ & $(13,2)$ \\
Lei & $-38 * * *$ & -8 & $102 * * *$ & $102 * * *$ & $169 * * *$ \\
& $(14,7)$ & $(14,7)$ & $(9,0)$ & $(9,0)$ & $(9,1)$ \\
Funcionário x Lei & $468^{* * *}$ & $484 * * *$ & $-567 * * *$ & $557 * * *$ & $571 * * *$ \\
& $(18,0)$ & $(18,1)$ & $(16,3)$ & $(16,3)$ & $(16,5)$ \\
Tendência de tempo & $0,001 * * *$ & $0,001 * * *$ & $0,001 * * *$ & $0,001 * * *$ & $0,001 * * *$ \\
& $(0,00001)$ & $(0,00001)$ & $(0,00001)$ & $(0,00001)$ & $(0,00001)$ \\
Origem de recursos & $-991 * * *$ & $-892 * * *$ & $-935 * * *$ & $-930 * * *$ & $-963 * * *$ \\
& $(9,6)$ & $(9,6)$ & $(8,4)$ & $(8,4)$ & $(8,2)$ \\
Risco & $-747 * * *$ & & $-762 * * *$ & $-766 * * *$ & $-928 * * *$ \\
& $(9,1)$ & & $(9,0)$ & $(8,9)$ & $(9,0)$ \\
Sexo & $6 * * *$ & $-4 * * *$ & & $62^{* * *}$ & $96 * * *$ \\
& $(8,5)$ & $(8,5)$ & & $(7,4)$ & $(7,5)$ \\
Renda Mensal & $-72,8 * * *$ & $-47,8 * * *$ & $8,9 * * *$ & & $26,6 * * *$ \\
& $(7,3)$ & $(7,3)$ & $(2,7)$ & & $(2,7)$ \\
\hline Obs & 1163200 & 1163200 & 1163200 & 1163200 & \\
$R^{2}$ & 0,16 & 0,15 & 0,13 & 0,13 & 0,11 \\
\hline \hline
\end{tabular}

$* * * \overline{\overline{\text { Estatisticamente Significante a 1\%;**Estatisticamente Significante a 5\%; *Estatisticam }}}$ ente

Significante a $10 \%$. Entre parênteses: erro padrão robusto. Apenas na coluna (V) não foram utilizadas as dummies dos municípios.

Vale notar a mudança de comportamento dos mutuário depois da instituição de uma lei que agiliza a retomada do bem financiado por parte do credor em caso de calote. Neste cenário, a variável dependente é a probabilidade do contrato estar em atraso, ou seja, a probabilidade da parcela do financiamento não ter sido paga em um período de até 90 dias desde o seu vencimento. Pela Tabela 6, verifica-se que, após agosto de 2004, a probabilidade do mutuário atrasar 
o pagamento das parcelas do empréstimo recuou em 0,2 ponto percentual.

Além disso, a probabilidade dos empregados privados atrasarem o pagamento é maior. Pela coluna (I), funcionários de instituições privadas atrasam em média 0,9 ponto percentual a mais os pagamentos do que os funcionários públicos. Entretanto, esse cenário se altera com a instituição da Lei de alienação fiduciária. Observando o coeficiente de interesse, a interação entre a dummy trabalhador privado e a lei, encontra-se que, depois de agosto de 2004, os funcionários privados atrasaram menos seus pagamentos, havendo uma queda de 0,08 ponto percentual.

Tabela 6: Variável dependente: Dummy atraso

\begin{tabular}{|c|c|c|c|c|}
\hline & (I) & (II) & (III) & (IV) \\
\hline \multirow[t]{2}{*}{ Funcionário Privado } & $0,009 * * *$ & $0,009 * * *$ & $0,009 * * *$ & $0,01 * * *$ \\
\hline & $(0,0004)$ & $(0,0004)$ & $(0,0004)$ & $(0,0004)$ \\
\hline \multirow[t]{2}{*}{ Lei } & $-0,002 * * *$ & $-0,002 * * *$ & $-0,001 * * *$ & $-0,002 * * *$ \\
\hline & $(0,0003)$ & $(0,0003)$ & $(0,0003)$ & $(0,0003)$ \\
\hline \multirow[t]{2}{*}{ Funcionário x Lei } & $-0,0008^{*}$ & $-0,0008 *$ & $-0,0006$ & $-0,001 * *$ \\
\hline & $(0,0005)$ & $(0,0005)$ & $(0,0005)$ & $(0,0005)$ \\
\hline \multirow[t]{2}{*}{ Tendência de tempo } & $-4,13 \mathrm{e}-09 * * *$ & $-4,13 \mathrm{e}-09 * * *$ & $-3,60 \mathrm{e}-0,9 * * *$ & $5,90 \mathrm{e}-09 * * *$ \\
\hline & $(5,72 \mathrm{e}-10)$ & $(5,72 \mathrm{e}-10)$ & $(5,72 \mathrm{e}-10)$ & $(4,70 \mathrm{e}-10)$ \\
\hline \multirow[t]{2}{*}{ Origem de recursos } & 0,0005 & 0,0005 & $-0,001 * * *$ & $-0,001 * * *$ \\
\hline & $(0,0003)$ & $(0,0003)$ & $(0,0003)$ & $(0,0003)$ \\
\hline \multirow[t]{2}{*}{ Risco } & $0,08 * * *$ & $0,08 * * *$ & $0,08^{* * *}$ & $0,08^{* * *}$ \\
\hline & $(0,0006)$ & $(0,0006)$ & $(0,0006)$ & $(0,0006)$ \\
\hline \multirow[t]{2}{*}{ Prazo } & $0,0002 * * *$ & $0,0002 * * *$ & $0,0002 * * *$ & $0,0003 * * *$ \\
\hline & $(0,00001)$ & $(0,00001)$ & $(0,00001)$ & $(0,00001)$ \\
\hline \multirow[t]{2}{*}{ Sexo } & $0,002 * * *$ & & $0,0007 * * *$ & $0,002 * * *$ \\
\hline & $(0,0002)$ & & $(0,0002)$ & $(0,0002)$ \\
\hline \multirow[t]{2}{*}{ Renda Mensal } & $-0,003 * * *$ & $-0,003 * * *$ & & $-0,002 * * *$ \\
\hline & $(0,0001)$ & $(0,0001)$ & & $(0,0001)$ \\
\hline \multirow[t]{2}{*}{ Montante } & $-5,06 \mathrm{e}-09 * * *$ & $-4,73 \mathrm{e}-09^{* * *}$ & $-1,19 \mathrm{e}-09^{* * *}$ & $-1,28 \mathrm{e}-09 * * *$ \\
\hline & $(8,36 \mathrm{e}-10)$ & $(8,33 \mathrm{e}-10)$ & $(9,47 \mathrm{e}-10)$ & $(4,70 \mathrm{e}-10)$ \\
\hline Obs & 1163200 & 1163200 & 1163200 & 1163200 \\
\hline$R^{2}$ & 0,06 & 0,06 & 0,06 & 0,06 \\
\hline
\end{tabular}

$* * * \overline{\overline{\text { Estatisticamente Significante a 1\%;**Estatisticamente Significante a 5\%; *Estatisticamente }}}$

Significante a 10\%. Entre parênteses: erro padrão robusto Apenas na coluna (IV) não foram utilizadas as dummies dos municípios. 
Quando analisada a variável prejuízo, ou seja, pagamentos atrasados há mais de 90 dias, tem-se que depois da introdução da Lei $\mathrm{n} \underline{0}$ 10.931, a probabilidade de default reduziu. Pela tabela 8, após agosto de 2004, a probabilidade de um empréstimo não ser pago recuou aproximadamente 0,2 ponto percentual. Todavia, assim como aconteceu no caso dos financiamentos em atraso, funcionários privados têm uma probabilidade 1,5 ponto percentual maior de não honrar com os seus pagamentos do que os servidores públicos.

Com relação à variável de interação, os resultados são menos conclusivos do que com relação aos modelos especificados anteriomente. O coeficiente só é estatisticamente significante quando não controlamos pela renda mensal do mutuário. Nesse caso, coluna (II), após a lei de alienação fiduciária, a probabilidade do funcionário privado não pagar o empréstimo aumentou, contrariamente ao que foi encontrado nas simulações anteriores.

Tabela 7: Variável dependente: Dummy prejuízo

\begin{tabular}{|c|c|c|c|c|}
\hline & (I) & (II) & (III) & (IV) \\
\hline Funcionário Privado & $\begin{array}{c}0,015 * * * \\
(0,0004)\end{array}$ & $\begin{array}{c}0,017 * * * \\
(0,0004)\end{array}$ & $\begin{array}{c}0,015 * * * \\
(0,0004)\end{array}$ & $\begin{array}{c}0,023 * * * \\
(0,0004)\end{array}$ \\
\hline Lei & $\begin{array}{c}-0,002 * * * \\
(0,0003)\end{array}$ & $\begin{array}{c}-0,001 * * * \\
(0,0003)\end{array}$ & $\begin{array}{c}-0,003 * * * \\
(0,0003)\end{array}$ & $\begin{array}{c}-0,003 * * * \\
(0,0003)\end{array}$ \\
\hline Funcionário x Lei & $\begin{array}{c}0,0007 \\
(0,0005)\end{array}$ & $\begin{array}{c}0,0015^{* * *} \\
(0,0005)\end{array}$ & $\begin{array}{c}0,0007 \\
(0,0005)\end{array}$ & $\begin{array}{l}-0,0004 \\
(0,0005)\end{array}$ \\
\hline Tendência de tempo & $\begin{array}{c}-8,50 \mathrm{e}-08^{* * * *} \\
(7,23 \mathrm{e}-10)\end{array}$ & $\begin{array}{c}-8,39 \mathrm{e}-08^{* * *} \\
(7,20 \mathrm{e}-10)\end{array}$ & $\begin{array}{c}-8,50 \mathrm{e}-0,8^{* * *} \\
(7,23 \mathrm{e}-10)\end{array}$ & $\begin{array}{c}-4,32 \mathrm{e}-08^{* * *} \\
(5,43 \mathrm{e}-10)\end{array}$ \\
\hline Origem de recursos & $\begin{array}{c}-0,04 * * * \\
(0,0004)\end{array}$ & $\begin{array}{c}-0,04 * * * \\
(0,0004)\end{array}$ & $\begin{array}{l}-0,04 * * * \\
(0,0004)\end{array}$ & $\begin{array}{c}-0,05 * * * \\
(0,0004)\end{array}$ \\
\hline Risco & $\begin{array}{l}0,10 * * * \\
(0,0006)\end{array}$ & $\begin{array}{l}0,11 * * * \\
(0,0006)\end{array}$ & $\begin{array}{l}0,10^{* * *} \\
(0,0006)\end{array}$ & $\begin{array}{l}0,10 * * * \\
(0,0006)\end{array}$ \\
\hline Prazo & $\begin{array}{c}-0,0009 * * * \\
(0,00001)\end{array}$ & $\begin{array}{c}-0,0009 * * * \\
(0,00001)\end{array}$ & $\begin{array}{c}-0,0008 * * * \\
(0,00001)\end{array}$ & $\begin{array}{c}-0,0005 * * * \\
(0,00001)\end{array}$ \\
\hline Sexo & $\begin{array}{c}0,004 * * * \\
(0,0002)\end{array}$ & $\begin{array}{c}0,004 * * * \\
(0,0002)\end{array}$ & & $\begin{array}{c}0,004 * * * \\
(0,0002)\end{array}$ \\
\hline Renda Mensal & $\begin{array}{r}-0,01 * * * \\
(0,0001)\end{array}$ & & $\begin{array}{c}-0,01 * * * \\
(0,0001)\end{array}$ & $\begin{array}{l}-0,01 * * * \\
(0,0001)\end{array}$ \\
\hline Montante & $\begin{array}{c}-3,20 \mathrm{e}-08 * * * \\
(2,97 \mathrm{e}-09)\end{array}$ & $\begin{array}{c}-5,65 \mathrm{e}-08^{* * *} \\
(4,10 \mathrm{e}-09)\end{array}$ & $\begin{array}{c}-3,13 \mathrm{e}-08 * * * \\
(2,93 \mathrm{e}-09)\end{array}$ & $\begin{array}{c}-8,59 \mathrm{e}-08 * * * \\
(-5,37 \mathrm{e}-09)\end{array}$ \\
\hline Obs & 1163200 & 1163200 & 1163200 & 1163200 \\
\hline$R^{2}$ & 0,18 & 0,17 & 0,17 & 0,13 \\
\hline
\end{tabular}

Significante a $10 \%$. Entre parênteses: erro padrão robusto. Apenas na coluna (IV) não foram utilizadas as dummies dos municípios.

Para a análise do impacto da Lei no 10.931 na probabilidade de atraso e default dos contratos imobiliários dos funcionários privados, também foram rodados modelos probit, que geraram 
resultados muito similares aos já expostos.

\subsection{Segunda Estratégia Empírica}

Na mesma linha de raciocínio, nesta segunda estratégia empírica, compara-se o impacto da Lei no 10.931 em grupos de mutuários com diferentes riscos. As instituições financeiras, com base em informações dos devedores como a situação econômica financeira, o grau de endividamento, o tempo de relacionamento, entre outros fatores, classificou os indivíduos em nove faixas de risco, que vão do AA, menos arriscado, até o $\mathrm{HH}$, com maior probabilidade de default.

De acordo com o modelo acima exposto, antes de agosto de 2004, as instituições financeiras com probabilidade muito pequena de recuperar a garantia em caso de não pagamento preferiam conceder empréstimos aos mutuários de menor risco. Entretanto, após a Lei no 10.931 , os bancos ampliaram a oferta de financiamento imobiliário para os indivíduos com maior risco, dada a facilidade de retomada do colateral, quando o mutuário não paga o empréstimo.

Neste cenário, definiu-se o grupo de controle como sendo os mutuários classificados como AA; enquanto, no grupo de tratamento, estão os devedores com as duas piores classificações de risco $\left(\mathrm{H} \mathrm{e} \mathrm{HH}^{20}\right.$. Os gráficos abaixo descrevem o número de contratos imobiliários iniciados entre os meses de agosto de 2003 e agosto de 2005, para os dois grupos.

\footnotetext{
${ }^{20}$ Vale ressaltar que estas classificações estão relacionadas ao índivíduo que toma o empréstimo e não à operação de crédito. Ainda, a análise da segunda estratégia empírica deve ser realizada com cautela, já que a nota do indivíduo deve ter forte correlação com a nota da operação, e operações HH são aquelas que já entraram em default)
} 
Figura 7: Evolução contratos grupo de controle (tipo AA)

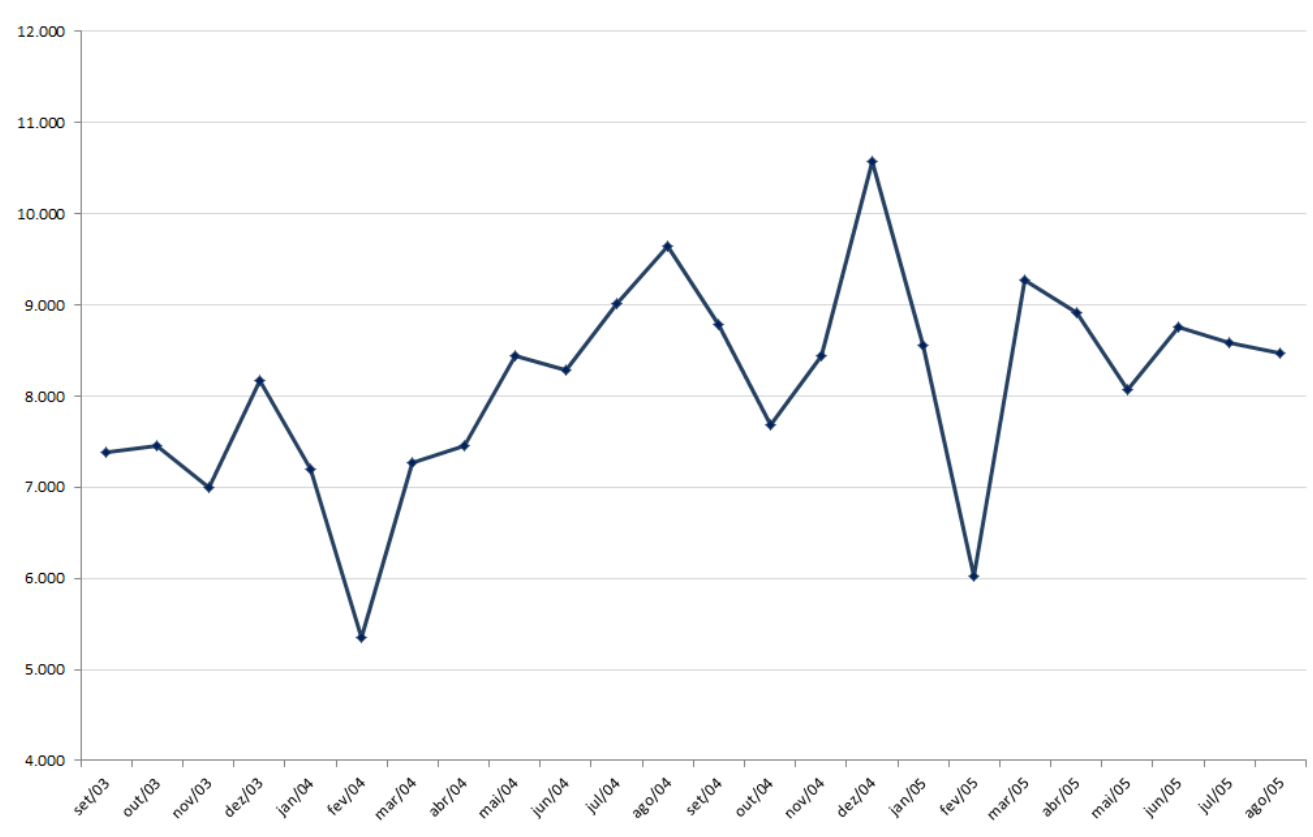

Figura 8: Evolução contratos grupo de tratamento (tipo $\mathrm{H}$ e $\mathrm{HH}$ )

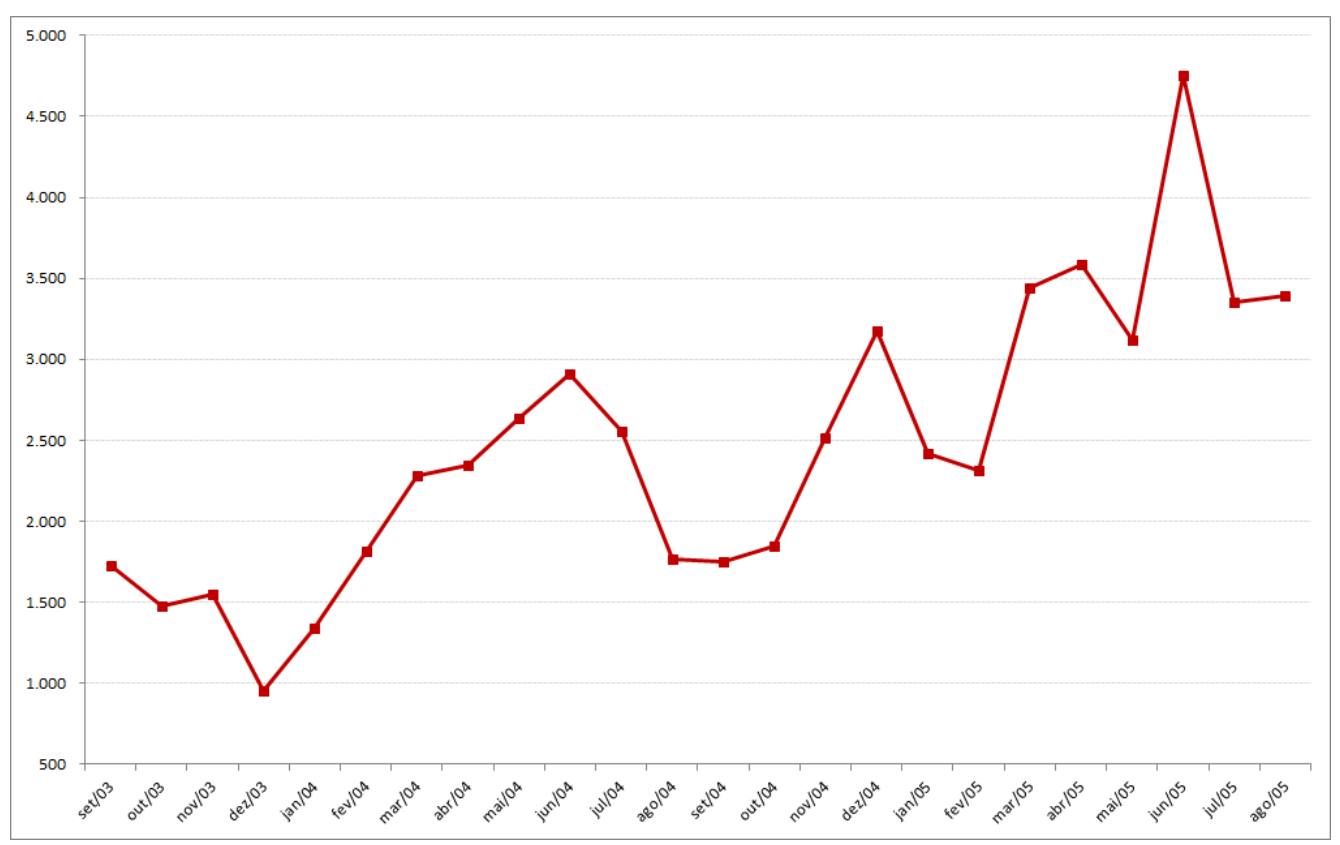

Assim, estima-se a seguinte equação:

$$
y_{i t}=\alpha+\beta_{1} \text { dlei }_{i t}+\beta_{2} \text { dtrat }_{i t}+\beta_{3} d t \text { ratle } i_{i t}+\gamma X_{i t}+\varepsilon_{i t}
$$

Onde $y_{i t}$ são as variáveis de interesse, que podem ser o valor financiado, o prazo do financiamento ou a probabilidade de atraso e default, no mês t, para cada contrato i. A variável dlei é 
uma dummy igual a um se a data de início do contrato for posterior a agosto de 2004, e zero caso contrário; dtrat também é uma dummy, que assume o valor zero quando o mutuário tem risco AA e um se lhe foi atribuído o risco $\mathrm{H}$ ou $\mathrm{HH}$; e dtratlei é a interação entre estas duas variáveis. $\mathrm{O}$ vetor $\mathrm{X}$ representa as variáveis de controle tanto para o contrato como para o mutuário.

Tabela 8: Grupo de controle vs. Grupo de tratamento

\begin{tabular}{ccc}
\hline \hline & Risco AA & Risco H e HH \\
\hline Número de observações & 12.936 & 3.696 \\
Renda Mensal & $5-10$ s.m. & $5-10$ s.m. \\
Proporção de homens & $45 \%$ & $60 \%$ \\
Idade & 55 anos & 43 anos \\
RM: Fortaleza & $1,0 \%$ & $1,5 \%$ \\
RM: Recife & $1,2 \%$ & $1,3 \%$ \\
RM: Salvador & $2,3 \%$ & $2 \%$ \\
RM: Belo Horizonte & $7 \%$ & $7 \%$ \\
RM: Rio de Janeiro & $15 \%$ & $13,2 \%$ \\
RM: São Paulo & $48 \%$ & $45 \%$ \\
RM: Curitiba & $5 \%$ & $8 \%$ \\
RM: Porto Alegre & $20,5 \%$ & $22 \%$ \\
Prazo & 10 anos & 12 anos \\
Montante financiado & R\$75.321 & R \$69.314 \\
Origem do recurso & $55 \%$ & $43 \%$ \\
Percentual de contratos atrasados & $0,2 \%$ & $3 \%$ \\
Percentual de prejuízos & $0 \%$ & $2 \%$ \\
\hline \hline
\end{tabular}

Utilizando esta nova especificação, encontra-se, novamente, que o valor financiado aumentou depois da instituição da lei. Pela coluna (I) na Tabela 10, após agosto de 2004, os contratos imobiliários passaram a ser, em média, $\mathrm{R} \$ 4.756$ superiores aos firmados antes da lei. Entretanto, analisando o montante do empréstimo entre os grupos de risco, não há evidências significativas de que existe uma diferença entre eles, embora os resultados apontem para um empréstimo menor aos agentes mais arriscados.

Além disso, a variável de interação entre a lei e o grupo de tratamento aponta para uma queda no valor do financiamento para os mutuários de maior risco, depois da lei de alienação fiduciária, diferentemente do que foi encontrado quando analisamos o impacto do aprimoramento jurídico 
entre funcionários públicos e privados.

Tabela 9: Variável dependente: Valor Financiado

\begin{tabular}{ccccc}
\hline \hline & (I) & (II) & (III) & (IV) \\
\hline \multirow{2}{*}{ Tratamento } & -2.967 & -2.603 & $-19.748 * * *$ & -15 \\
& $(5.173)$ & $(5.118)$ & $(5.555)$ & $(5.048)$ \\
Lei & $4.756 * * *$ & $4.639 * * *$ & $4.489 * * *$ & $4.621^{* * *}$ \\
& $(1.056)$ & $(1.058)$ & $(1.101)$ & $(1.071)$ \\
Tratamento x Lei & $-11.767 * *$ & $-11.713 * *$ & -8.463 & $-13.249 * *$ \\
& $(5.422)$ & $(5.367)$ & $(5.845)$ & $(5.048)$ \\
Tendência de tempo & $-0,014 * * *$ & $-0,012 * * *$ & $-0,012 * * *$ & $-0,013 * * *$ \\
& $(0,001)$ & $(0,001)$ & $(0,001)$ & $(0,001)$ \\
Origem de recursos & $4.990^{* *}$ & $4.423 *$ & $2.544 * *$ & 2.885 \\
& $(2.451)$ & $(2.452)$ & $(2.544)$ & $(2.510)$ \\
Sexo & $10.326 * * *$ & & $16.720 * * *$ & $8.991 * * *$ \\
& $(784)$ & & $(809)$ & $(789)$ \\
Renda Mensal & $14.447 * * *$ & $15.000^{* * *}$ & & $14.376 * * *$ \\
& $(337)$ & $(336)$ & & $(345)$ \\
\hline Obs & 30801 & 30801 & 30801 & 30801 \\
$R^{2}$ & 0,26 & 0,25 & 0,19 & 0,23 \\
\hline \hline
\end{tabular}

Significante a $10 \%$. Entre parênteses: erro padrão robusto. Apenas na coluna (IV) não foram utilizadas as dummies dos municípios.

Considerando a base como um todo, não encontamos resultado estatisticamente significativo para o impacto da Lei no 10.931 no prazo do contrato. Entretanto, há efeitos distintos do aprimoramento jurídico no montante do empréstimo considerando os diferentes grupos de risco. Para indivíduos com rating $\mathrm{H}$ e $\mathrm{HH}$, o prazo dos empréstimos é cerca de 1.113 dias inferior aos dos contratos oferecidos aos clientes AA. Por outro lado, depois da Lei no 10.931 , os mutuáros mais arriscados tiveram um alongamento de dois anos na maturidade dos seus contratos. 
Tabela 10: Variável dependente: Prazo do financiamento

\begin{tabular}{ccccc}
\hline \hline & $(\mathrm{I})$ & $(\mathrm{II})$ & $(\mathrm{III})$ & $(\mathrm{IV})$ \\
\hline \multirow{2}{*}{ Tratamento } & $-1.113 * * *$ & $-1.148^{* * *}$ & $-930^{* * *}$ & $-3.373 * * *$ \\
Lei & $(289)$ & $(294)$ & $(277)$ & $(369)$ \\
& 25 & 34 & 34 & -45 \\
Tratamento x Lei & $(42)$ & $(42)$ & $(42)$ & $(53)$ \\
& $797 * * *$ & $800^{* * *}$ & $753 * * *$ & $1.143 * * *$ \\
Tendência de tempo & $0,001 * * *$ & $0,001 * * *$ & $0,001 * * *$ & $0,001 * * *$ \\
& $(0,00001)$ & $(0,00001)$ & $(0,00001)$ & $(0,00001)$ \\
Origem de recursos & $354 * * *$ & $392 * * *$ & $350 * * *$ & $827 * * *$ \\
& $(126)$ & $(392)$ & $(350)$ & $(826)$ \\
Sexo & $-580^{* * *}$ & & $-650 * * *$ & $-1.312^{* * *}$ \\
& $(31)$ & & $(30)$ & $(38)$ \\
Renda Mensal & $-183 * * *$ & $-212^{* * *}$ & & $-476 * * *$ \\
& $(13)$ & $(13)$ & & $(15)$ \\
\hline Obs & 30801 & 30801 & 30801 & 30801 \\
$R^{2}$ & 0,55 & 0,55 & 0,55 & 0,23 \\
\hline \hline
\end{tabular}

***Estatisticamente Significante a 1\%;**Estatisticamente Significante a 5\%; *Estatisticamente

Significante a $10 \%$. Em parênteses erro padrão robusto Apenas na coluna (IV) não foi utilizada as dummys dos municípios

As tabelas 12 e 13 mostram resultados distintos aos encontrados na primeira especificação do estudo, utilizando funcionários públicos e privados. Apesar da intuição inicial de que, após a Lei, o número de contratos atrasados seria reduzido, já que o banco poderia retormar o colateral de forma facilitada em caso de default, gerando um incetivo extra ao mutuário para honrar o seu compromisso com o credor, pagando as parcelas em dia, nesse caso, não foi o que aconteceu. Com a facilidade de retomada do bem garantido, um número maior de clientes mais arriscados tiveram acesso ao crédito, o que aumentou no geral os atrasos e a taxa de inadimplência do financiamento imobiliário. Com relação aos atrasos, depois de agosto de 2004, os contratos que ainda não foram pagos e estavam vencidos há menos de 90 dias aumentaram em 0,1 ponto percentual. O mesmo aconteceu para os casos de default, que aumentaram 0,1 ponto percentual após a Lei $\mathrm{n}^{\underline{o}} 10.931$.

Além disso, estes resultados apontam que indivíduos dos grupos de risco H e HH têm 25 pontos 
percentuias a mais de probabilidade de atrasarem as parcelas e 11 pontos percentuais a mais de chance de dar default do que os mutuários rating $A A$. Entretanto, depois da lei, o atraso do grupo de tratamento registrou um leve recuo, de 0,07 ponto percentual, embora esse resultado não seja estatisticamente significante. Com relação aos contratos inadimplentes, mesmo depois da lei de alienação fiduciária, a probabilidade de um indivíduo de maior risco não honrar com o pagamento é ainda maior, 6 pontos percentuais, sugerindo que, para este grupo de risco, a instiuição da lei não surtiu o efeito desejado.

Tabela 11: Variável dependente: Dummy atraso

\begin{tabular}{ccccc}
\hline \hline & $(\mathrm{I})$ & $(\mathrm{II})$ & $(\mathrm{III})$ & $(\mathrm{IV})$ \\
\hline \multirow{2}{*}{ Tratamento } & $0,25^{* * *}$ & $0,25^{* * *}$ & $0,25^{* * *}$ & $0,29 * * *$ \\
& $(0,04)$ & $(0,04)$ & $(0,04)$ & $(0,05)$ \\
Lei & $0,001^{* * *}$ & $0,001^{* * *}$ & $0,001^{* * *}$ & 0,001 \\
& $(0,0002)$ & $(0,0002)$ & $(0,0002)$ & $(0,00008)$ \\
Tratamento x Lei & $-0,0007$ & $-0,0007$ & $-0,0004$ & $-0,0003$ \\
& $(0,05)$ & $(0,05)$ & $(0,05)$ & $(0,05)$ \\
Tendência de tempo & $-4,35 \mathrm{e}-09^{* * *}$ & $-4,26 \mathrm{e}-09^{* * *}$ & $-4,20 \mathrm{e}-0,9 * * *$ & $5,10 \mathrm{e}-09 * * *$ \\
& $(5,54 \mathrm{e}-10)$ & $(5,25 \mathrm{e}-10)$ & $(5,54 \mathrm{e}-10)$ & $(4,30 \mathrm{e}-10)$ \\
Origem de recursos & $-0,013^{* *}$ & $-0,013^{* *}$ & $-0,013^{* *}$ & $-0,005$ \\
& $(0,006)$ & $(0,006)$ & $(0,006)$ & $(0,006)$ \\
Prazo & $0,0004 * * *$ & $0,0004 * * *$ & $0,0004 * * *$ & $0,0001 * * *$ \\
& $(0,00005)$ & $(0,00005)$ & $(0,00004)$ & $(0,00004)$ \\
Valor Financiado & $3,28 \mathrm{e}-08^{* * *}$ & $3,37 \mathrm{e}-08^{* * *}$ & $3,97 \mathrm{e}-08^{* * * *}$ & $2,67 \mathrm{e}-08^{* * *}$ \\
& $(4,79 \mathrm{e}-09)$ & $(4,75 \mathrm{e}-09)$ & $(4,82 \mathrm{e}-09)$ & $(4,54 \mathrm{e}-09)$ \\
Sexo & $0,002^{*}$ & & $0,002^{* *}$ & 0,001 \\
& $(0,0008)$ & & $(0,0008)$ & $(0,0008)$ \\
Renda Mensal & $0,001^{* * *}$ & $0,001^{* * *}$ & & $0,001 * * *$ \\
& $(0,0004)$ & $(0,0004)$ & & $(0,0004)$ \\
\hline Obs & 30801 & 30801 & 30801 & 30801 \\
$R^{2}$ & 0,34 & 0,34 & 0,34 & 0,30 \\
\hline
\end{tabular}

$* * * \overline{\overline{\text { Estatisticamente Significante a 1\%;**Estatisticamente Significante a 5\%; *Estatisticamente }}}$

Significante a $10 \%$. Entre parênteses: erro padrão robusto Apenas na coluna (IV) não foram utilizadas as dummies dos municípios. 
Tabela 12: Variável dependente: Dummy prejuízo

\begin{tabular}{|c|c|c|c|c|}
\hline & (I) & (II) & (III) & (IV) \\
\hline \multirow[t]{2}{*}{ Tratamento } & $0,11^{* * *}$ & $0,11 * * *$ & $0,11 * * *$ & $0,16^{* * *}$ \\
\hline & $(0,04)$ & $(0,04)$ & $(0,04)$ & $(0,04)$ \\
\hline \multirow[t]{2}{*}{ Lei } & $0,001 * * *$ & $0,001 * * *$ & $0,001 * * *$ & 0,0001 \\
\hline & $(0,0003)$ & $(0,0003)$ & $(0,0003)$ & $(0,0001)$ \\
\hline \multirow[t]{2}{*}{ Tratamento x Lei } & $0,06^{*}$ & $0,06^{*}$ & $0,06^{*}$ & $0,08^{*}$ \\
\hline & $(0,04)$ & $(0,04)$ & $(0,04)$ & $(0,04)$ \\
\hline \multirow[t]{2}{*}{ Tendência de tempo } & $-8,23 \mathrm{e}-08 * * *$ & $-8,50 \mathrm{e}-08 * * *$ & $-8,20 \mathrm{e}-0,8 * * *$ & $8,37 \mathrm{e}-08 * * *$ \\
\hline & $(7,44 \mathrm{e}-10)$ & $(7,20 \mathrm{e}-10)$ & $(7,23 e-10)$ & $(7,30 \mathrm{e}-10)$ \\
\hline \multirow[t]{2}{*}{ Origem de recursos } & $0,012 * * *$ & $0,012 * * *$ & $0,012 * * *$ & $0,016^{* * *}$ \\
\hline & $(0,003)$ & $(0,003)$ & $(0,003)$ & $(0,004)$ \\
\hline \multirow[t]{2}{*}{ Prazo } & $-0,0007 * * *$ & $-0,0007 * * *$ & $-0,0007 * * *$ & $-0,0006 * * *$ \\
\hline & $(0,00005)$ & $(0,00005)$ & $(0,00004)$ & $(0,00004)$ \\
\hline \multirow[t]{2}{*}{ Valor Financiado } & $4,28 \mathrm{e}-08 * * *$ & $4,29 \mathrm{e}-08 * * *$ & $3,18 \mathrm{e}-08 * * *$ & $1,97 \mathrm{e}-08^{* * *}$ \\
\hline & $(3,75 e-09)$ & $(3,73 e-09)$ & $(3,01 \mathrm{e}-09)$ & $(2,49 \mathrm{e}-09)$ \\
\hline \multirow[t]{2}{*}{ Sexo } & $-0,002$ & & 0,003 & 0,002 \\
\hline & $(0,0007)$ & & $(0,0007)$ & $(0,0007)$ \\
\hline \multirow[t]{2}{*}{ Renda Mensal } & $0,002 * * *$ & $0,002 * * *$ & & $0,001 * * *$ \\
\hline & $(0,0004)$ & $(0,0004)$ & & $(0,0004)$ \\
\hline Obs & 30801 & 30801 & 30801 & 30801 \\
\hline$R^{2}$ & 0,32 & 0,32 & 0,32 & 0,25 \\
\hline
\end{tabular}

$* * * \overline{\overline{E s t a t i s t i c a m e n t e ~ S i g n i f i c a n t e ~ a ~ 1 \% ; * * E s t a t i s t i c a m e n t e ~ S i g n i f i c a n t e ~ a ~ 5 \% ; ~ * E s t a t i s t i c a m e n t e ~}}$

Significante a 10\%. Entre parênteses: erro padrão robusto Apenas na coluna (IV) não foram utilizadas as dummies dos municípios

Com a hipótese de que a Lei $\mathrm{n}^{\underline{o}} 10.931$ não tenha surtido o efeito desejado nos grupos de risco elevado (H e HH), modificou-se esta segunda especificação, determinando como grupo de tratamento, mutuários com rating D. Abaixo, encontra-se a evolução dos contratos dos agentes de risco D. 
Figura 9: Evolução contratos grupo de controle (tipo D)

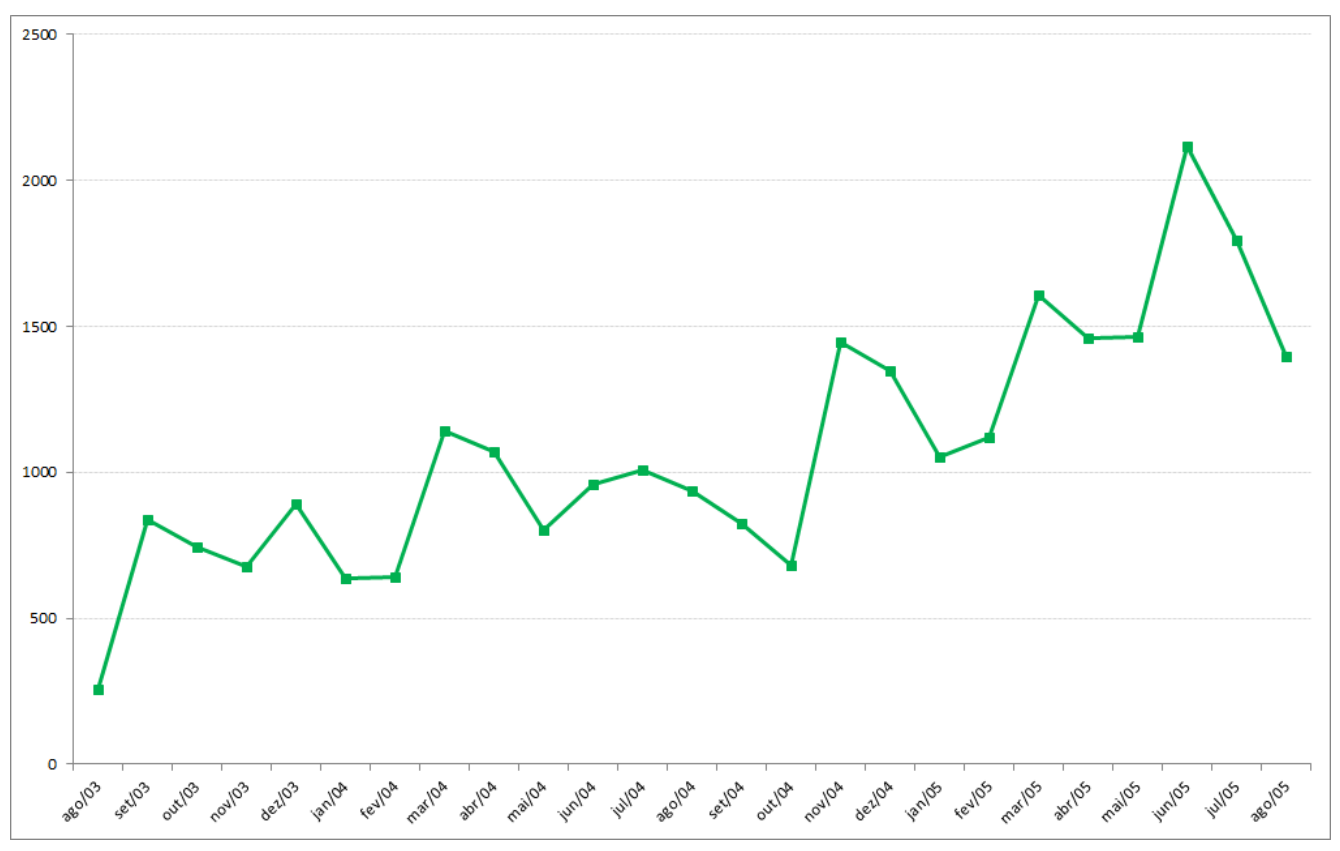

Considerando apenas o impacto da Lei de alienação fiduciária na probabilidade de atraso e de default, os indivíduos com grau médio de risco têm uma probablidade 10 pontos percentuais superior de atrasar os pagamentos e 5 pontos percentuais de dar default. Entretanto, depois da lei, os mutuários com rating $\mathrm{D}$ têm probabilidade 0,01 ponto percentual menor de não pagar os empréstimos, sinalizando que, para individuos com grau médio de risco, o aprimoramento jurídico teve um efeito positivo ao incentivar os tomadores de empréstimos a cumprir com as suas obrigações ${ }^{21}$.

\section{CONCLUSÃO}

A Lei $\mathrm{n}^{o}$ 10.931, ao incluir definitivamente a figura jurídica da alienação fiduciária do bem imóvel no ordenamento jurídico brasileiro, dando maior segurança ao credor, permitiu que os bancos não só ampliassem a concessão de financimento habitacional, como também alterassem os principais termos dos contratos. O presente estudo, com o objetivo de analisar o impacto da Lei $\mathrm{n} \underline{o} 10.931$ sobre o mercado de crédito imobiliário, encontrou que este aprimoramento jurídico teve efeito significativo nos termos dos contratos e no comportamento dos mutúarios. Mais do que isso, a Lei gerou impactos distintos dependendo do tipo de tomador de empréstimo, servidor público ou privado, agente de maior ou menor risco.

\footnotetext{
${ }^{21}$ As tabelas das simulações com o grupo de tratamento sendo representado pelos mutuários rating $\mathrm{D}$ estão no Apêndice deste estudo.
} 
Em um primeiro momento, considerando o impacto da Lei nos contratos de funcionários privados, temos que o aprimoramento jurídico não só proporcionou que mais trabalhadores de entidades privadas tivessem maior acesso a esta modalidade de crédito, como também fez com que seus contratos tivessem um montante maior e prazos mais longos. Além disso, ao facilitar a retomada do colateral pelo banco em caso de default, a Lei também reduziu a probabilidade de atrasos e prejuízos dos funcionários privados.

Já na comparação entre diferentes grupos de risco, se observa, além da maior concessão de crédito ao mais arriscados $(\mathrm{H}$ e $\mathrm{HH})$, que o prazo de financiamento destes contratos também foi estendido com a Lei. Entretanto, não se encontra o mesmo resultado para o valor do empréstimo. Depois de agosto de 2004, mutuarios rating $\mathrm{H}$ e $\mathrm{HH}$ tiveram o valor dos seus empréstimos reduzidos.

Além disso, os resultados sugerem que a Lei $\mathrm{n}^{o}$ 10.931 foi menos eficiente, no sentido de garantir o pagamento dos empréstimos aos credores, para aqueles grupos considerados de alto grau de risco $(\mathrm{H}$ e $\mathrm{HH})$. Neste caso, mesmo após a instituição do aprimoramento jurídico, os mutuários mais arriscados aumentaram a probabilidade de default. Já quando confrontado o efeito da Lei sobre indivíduos com risco médio (rating D), tem-se que a Lei $\mathrm{n}-10.931$ foi eficaz para reduzir tanto atrasos como prejuízos deste grupo.

Por fim, o presente trabalho concluiu que a Lei $\mathrm{n}^{\underline{o}} 10.931$ foi importante para a atual evolução do mercado de crédito imobiliário do país, ao possibilitar que as instituições financeiras ampliassem a oferta de financiamentos habitacionais e aprimorassem os termos dos contratos, através do aumento do valor do empréstimo e do alongamento dos prazos dos financiamentos. Esta dissertação é apenas um estudo inicial sobre o impacto de aprimoramentos jurídicos no mercado de crédito imobiliário no Brasil. Apesar do alto grau de déficit habitacional no país e da relevância do tema, ainda há uma relativa escassez de estudos econométricos acerca do assunto. Sugere-se, para estudos futuros, a análise do impacto da Lei $\mathrm{n}^{\underline{o}}$ 10.931, comparando-se modalidades distintas de empréstimos para um mesmo mutuário; além do exame dos efeitos de outros aprimoramentos jurídicos, como a Lei $\mathrm{n}-11.922$, de 13 de abril de 2009, que facultou a renegociação de contratos desequilibrados no mercado de crédito imobiliário. 



\section{Referências Bibliográficas}

BANERJEE, Abhijit V.; NEWMAN Andrew F. "Occupational Choice and the Process of Development." Journal of Political Economy. Vol. 101, n. 2, 1993, pp. 274-298.

BARRO, Robert J. "The Loan Market, Collateral, and Rates of Interest." Journal of Money, Credit and Banking. Vol. 8, n. 4, 1976, pp. 436-456.

BESANKO, David; THAKOR, Anjan V. "Collateral and Rationing: Sorting Equilibria in Monopolistic and Competitive Credit Markets”. International Economic Review. Vol. 28, n. 3, 1987, pp.671-689.

BESTER, Helmut. "Association Screening vs. Rationing in Credit Markets with Imperfect Information". The American Economic Review. Vol. 75, n. 4, 1985, pp. 850-855.

BRASIL. Senado Federal. Relatório apresentado pelo Senador Marco Maciel Projeto de Lei do Senado n. 229, de 2003, do Senador Delcídio Amaral. Disponível em: http://legis.senado.gov.br/mate-pdf/64731.pdf. Acesso em: 17/10/2014.

BRASIL. Lei n ${ }^{-}$9.514, de 20 de novembro de 1997. Dispõe sobre o Sistema de Financiamento Imobiliário. Presidência da República, Casa Civil, Subchefia para assuntos jurídicos, Brasília.

BRASIL. Lei $\mathrm{n}^{\underline{o}}$ 10.931, de 4 de agosto de 2004. Dispõe sobre o patrimônio de afetação de incorporações imobiliárias. Presidência da República, Casa Civil, Subchefia para assuntos jurídicos, Brasília.

CHAN, Yuk-Shee; THAKOR, Anjan V. "Collateral and Competitive Equilibra with Moral Hazerd and Private Information.” The Journal of Finance. Vol. 42, n. 2, 1987, pp.345-364.

COSTA, Ana A. "Mercado de crédito: uma análise econométrica dos volumes de crédito total e habitacional no Brasil.” Mimeo, 2004.

EDELBERG, W. 'Testing for Adverse Selection and Moral Hazard in Consumer Loan Markets". Mimeo, 2004.

ENDERS, W. Applied econometric time series,2004. 
EVANS, David ; JOVANOVIC, Boyan. "An Estimated Model of Entrepreneurship Choice under Liquidity Constraints." Journal of Political Economy. Vol. 97, n. 4, 1989, pp.808-827.

JAFFEE, Dwight M. ’Imperfect Information, Uncertainty, and Credit Rationing.” The Quarterly Journal of Economics. Vol. 90, n. 4, 1976, pp. 651-666.

MARTINS, Bruno S.; LUNDBERG, Luis E.; TAKEDA, Tony. "Crédito Habitacional no Brasil: aperfeiçoamentos institucionais e avaliação da evolução recente." Relatório de Economia Bancária e Crédito do Banco Central do Brasil., 2008, pp. 72-96.

ROTHSCHILD, M.; STIGLITZ Joseph E. "Equilibrium in Competitive Insurance Markets: An Essay on the Economics of Imperfect Information". Quarterly Journal of Economics, vol. 90, 1976, pp. 629-649.

STIGLITZ, Joseph E.; WEISS, Andrew. "Credit Rationing in Markets with Impefection Information." The American Economic Review. vol. 71, 1981, pp. 393-410.

THAKORA, V.; CALLAWAY R. "Costly Information Production Equilibria in the Bank Credit Market with Applications to Credit Rationing”. Journal of Financial and Quantitative Analysis, 1983, pp. 229-56.

VISARIA, Sujata. "Legal Reform and Loan Repayment:The Microeconomic Impact of Debt Recovery Tribunals in India.” American Economic Journal: Applied Economis. Vol. 1, n. 3, 2009, pp. 59-81.

WETTE, Hildegard C. "Collateral in Credit Rationing in Markets with Imperfect Information." American Economic Review. Vol. 73, 1983, pp. 442-445. 


\section{APÊNDICE}

Figura 10: Evolução da probabilidade de atraso

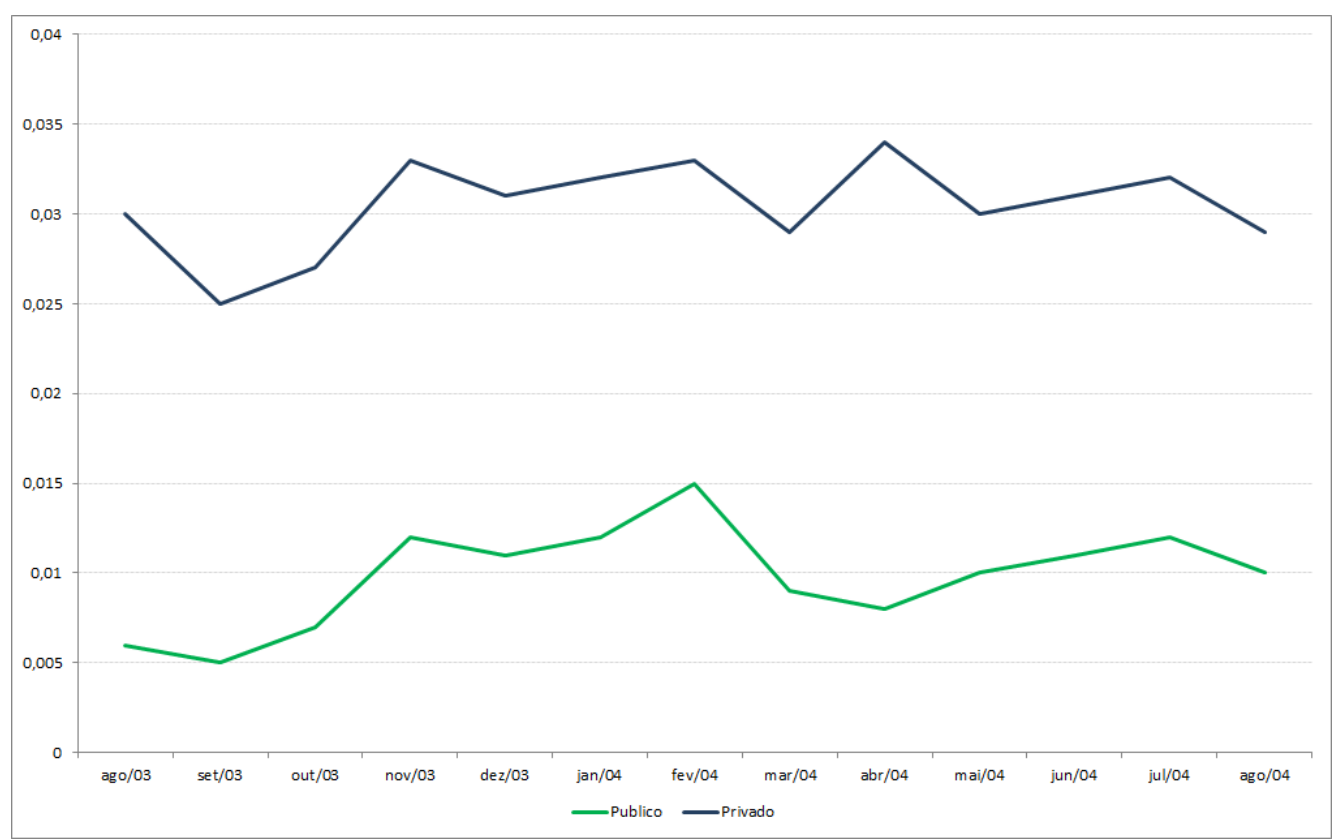

Figura 11: Evolução da probabilidade de default

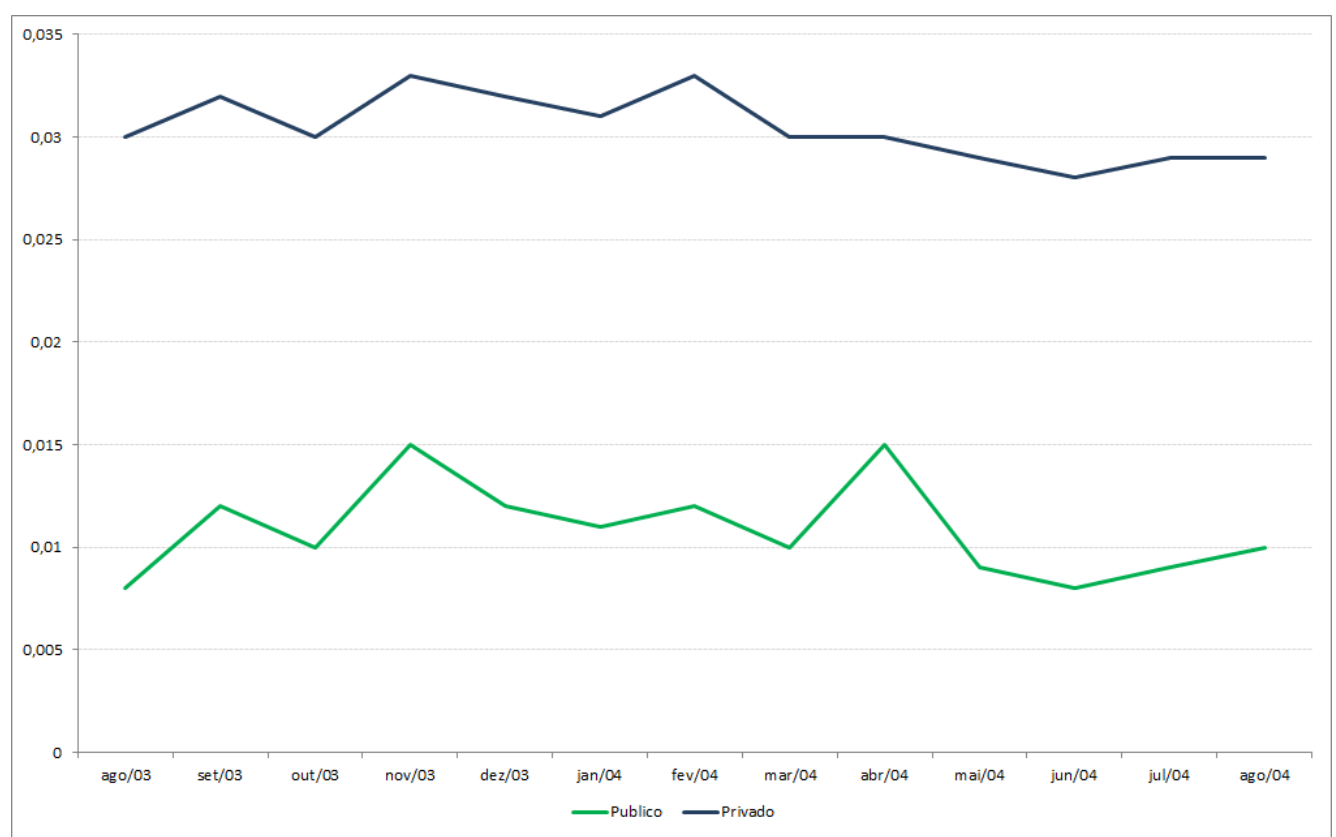


Tabela 13: Grupo de controle vs. Grupo de tratamento

\begin{tabular}{ccc}
\hline \hline & Risco AA & Risco D \\
\hline Número de observações & 12.936 & 3.806 \\
Renda Mensal & $5-10$ s.m. & $5-10$ s.m. \\
Proporção de homens & $45 \%$ & $53 \%$ \\
Idade & 55 anos & 47 anos \\
RM: Fortaleza & $1,0 \%$ & $1,3 \%$ \\
RM: Recife & $1,2 \%$ & $1,8 \%$ \\
RM: Salvador & $2,3 \%$ & $3,2 \%$ \\
RM: Belo Horizonte & $7 \%$ & $6,8 \%$ \\
RM: Rio de Janeiro & $15 \%$ & $15,2 \%$ \\
RM: São Paulo & $48 \%$ & $47 \%$ \\
RM: Curitiba & $5 \%$ & $6 \%$ \\
RM: Porto Alegre & $20,5 \%$ & $18,7 \%$ \\
Prazo & 10 anos & 9 anos \\
Montante financiado & R\$75.321 & R \$ 70.187 \\
Origem do recurso & $55 \%$ & $45 \%$ \\
Percentual de contratos atrasados & $0,2 \%$ & $2,7 \%$ \\
Percentual de prejuízos & $0 \%$ & $1,5 \%$ \\
\hline \hline
\end{tabular}


Tabela 14: Variável dependente: Dummy atraso

\begin{tabular}{|c|c|c|c|c|}
\hline & (I) & (II) & (III) & (IV) \\
\hline \multirow[t]{2}{*}{ Tratamento } & $0,10 * * *$ & $0,10 * * *$ & $0,10 * * *$ & $0,10 * * *$ \\
\hline & $(0,04)$ & $(0,04)$ & $(0,04)$ & $(0,05)$ \\
\hline \multirow[t]{2}{*}{ Lei } & $0,001 * * *$ & $0,001 * * *$ & $0,001 * * *$ & 0,001 \\
\hline & $(0,0002)$ & $(0,0002)$ & $(0,0002)$ & $(0,0002)$ \\
\hline \multirow[t]{2}{*}{ Tratamento x Lei } & $-0,0002 * * *$ & $-0,0002 * * *$ & $-0,0003 * * *$ & $-0,0003 * * *$ \\
\hline & $(0,00001)$ & $(0,00001)$ & $(0,00001)$ & $(0,00001)$ \\
\hline \multirow[t]{2}{*}{ Tendência de tempo } & $-3,46 \mathrm{e}-09 * * *$ & $-4,55 \mathrm{e}-09 * * *$ & $-4,22 \mathrm{e}-0,9 * * *$ & $5,13 \mathrm{e}-09 * * *$ \\
\hline & $(5,33 \mathrm{e}-10)$ & $(5,21 \mathrm{e}-10)$ & $(5,21 \mathrm{e}-10)$ & $(4,22 \mathrm{e}-10)$ \\
\hline \multirow[t]{2}{*}{ Origem de recursos } & $-0,012 * *$ & $-0,013 * *$ & $-0,013 * *$ & $-0,006$ \\
\hline & $(0,006)$ & $(0,006)$ & $(0,006)$ & $(0,006)$ \\
\hline \multirow[t]{2}{*}{ Prazo } & $0,0003 * * *$ & $0,0003 * * *$ & $0,0003 * * *$ & $0,0001 * * *$ \\
\hline & $(0,00005)$ & $(0,00005)$ & $(0,00004)$ & $(0,00004)$ \\
\hline \multirow[t]{2}{*}{ Valor Financiado } & $2,22 \mathrm{e}-08 * * *$ & $3,31 \mathrm{e}-08 * * *$ & $3,14 \mathrm{e}-08 * * *$ & $2,70 \mathrm{e}-08 * * *$ \\
\hline & $(4,59 \mathrm{e}-09)$ & $(4,43 e-09)$ & $(4,65 \mathrm{e}-09)$ & $(4,35 \mathrm{e}-09)$ \\
\hline \multirow[t]{2}{*}{ Sexo } & $0,002 *$ & & $0,002 * *$ & 0,001 \\
\hline & $(0,0008)$ & & $(0,0008)$ & $(0,0008)$ \\
\hline \multirow[t]{2}{*}{ Renda Mensal } & $0,001 * * *$ & $0,001 * * *$ & & $0,001 * * *$ \\
\hline & $(0,0004)$ & $(0,0004)$ & & $(0,0004)$ \\
\hline Obs & 30018 & 30018 & 30018 & 30018 \\
\hline$R^{2}$ & 0,25 & 0,25 & 0,25 & 0,22 \\
\hline
\end{tabular}

$* * * \overline{\overline{E s t a t i s t i c a m e n t e ~ S i g n i f i c a n t e ~ a ~ 1 \% ; * * E s t a t i s t i c a m e n t e ~ S i g n i f i c a n t e ~ a ~ 5 \% ; ~ * E s t a t i s t i c a m e n t e ~}}$

Significante a 10\%. Entre parênteses: erro padrão robusto Apenas na coluna (IV) não foram utilizadas as dummies dos municípios. 
Tabela 15: Variável dependente: Dummy prejuízo

\begin{tabular}{|c|c|c|c|c|}
\hline & (I) & (II) & (III) & (IV) \\
\hline \multirow[t]{2}{*}{ Tratamento } & $0,5 * * *$ & $0,5 * * *$ & $0,5^{* * *}$ & $0,6^{* * *}$ \\
\hline & $(0,04)$ & $(0,04)$ & $(0,04)$ & $(0,04)$ \\
\hline \multirow[t]{2}{*}{ Lei } & $0,001 * * *$ & $0,001 * * *$ & $0,001 * * *$ & 0,0001 \\
\hline & $(0,0003)$ & $(0,0003)$ & $(0,0003)$ & $(0,0002)$ \\
\hline \multirow[t]{2}{*}{ Tratamento x Lei } & $-0,0001 * * *$ & $-0,0001 * * *$ & $-0,0001 * * *$ & $-0,0003^{*}$ \\
\hline & $(0,00002)$ & $(0,00002)$ & $(0,00002)$ & $(0,00002)$ \\
\hline \multirow[t]{2}{*}{ Tendência de tempo } & $-8,54 \mathrm{e}-08 * * *$ & $-8,52 \mathrm{e}-08 * * *$ & $-8,30 \mathrm{e}-0,8 * * *$ & $8,14 \mathrm{e}-08 * * *$ \\
\hline & $(7,44 \mathrm{e}-10)$ & $(7,99 \mathrm{e}-10)$ & $(7,33 \mathrm{e}-10)$ & $(7,10 \mathrm{e}-10)$ \\
\hline \multirow[t]{2}{*}{ Origem de recursos } & $0,012 * * *$ & $0,012 * * *$ & $0,012 * * *$ & $0,012 * * *$ \\
\hline & $(0,003)$ & $(0,003)$ & $(0,003)$ & $(0,004)$ \\
\hline \multirow[t]{2}{*}{ Prazo } & $-0,0005 * * *$ & $-0,0005 * * *$ & $-0,0007 * * *$ & $-0,0006 * * *$ \\
\hline & $(0,00005)$ & $(0,00005)$ & $(0,00004)$ & $(0,00004)$ \\
\hline \multirow[t]{2}{*}{ Valor Financiado } & $4,28 \mathrm{e}-08 * * *$ & $4,29 \mathrm{e}-08 * * *$ & $3,18 \mathrm{e}-08 * * *$ & $1,97 \mathrm{e}-08 * * *$ \\
\hline & $(3,56 \mathrm{e}-09)$ & $(3,87 e-09)$ & $(3,91 \mathrm{e}-09)$ & $(2,48 \mathrm{e}-09)$ \\
\hline \multirow[t]{2}{*}{ Sexo } & 0,002 & & 0,003 & 0,002 \\
\hline & $(0,0007)$ & & $(0,0007)$ & $(0,0007)$ \\
\hline \multirow[t]{2}{*}{ Renda Mensal } & $0,002 * * *$ & $0,002 * * *$ & & $0,001 * * *$ \\
\hline & $(0,0004)$ & $(0,0004)$ & & $(0,0004)$ \\
\hline Obs & 30018 & 30018 & 30018 & 30018 \\
\hline$R^{2}$ & 0,30 & 0,30 & 0,30 & 0,28 \\
\hline
\end{tabular}

*** $\overline{\overline{\text { Estatisticamente Significante a 1\%;**Estatisticamente Significante a 5\%; *Estatisticamente }}}$

Significante a 10\%. Entre parênteses: erro padrão robusto Apenas na coluna (IV) não foram utilizadas as dummies dos municípios. 